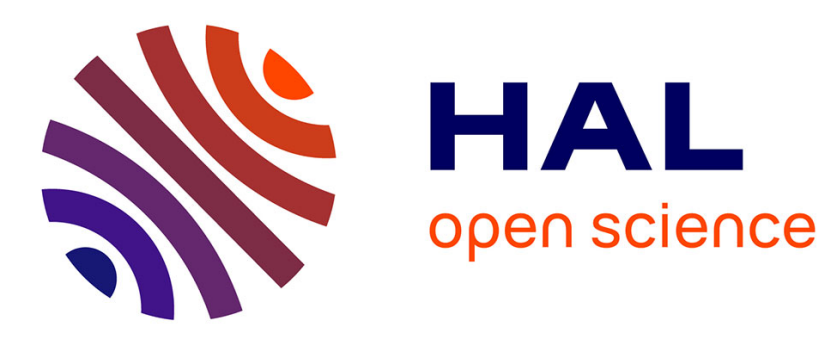

\title{
How do reservation prices impact distressed debt rescheduling?
}

\author{
Franck Moraux, Patrick Navatte
}

\section{To cite this version:}

Franck Moraux, Patrick Navatte. How do reservation prices impact distressed debt rescheduling?. Economic Modelling, 2015, 46, pp.269-282. 10.1016/j.econmod.2014.12.004 . halshs-01116887

\section{HAL Id: halshs-01116887 https://shs.hal.science/halshs-01116887}

Submitted on 3 Apr 2015

HAL is a multi-disciplinary open access archive for the deposit and dissemination of scientific research documents, whether they are published or not. The documents may come from teaching and research institutions in France or abroad, or from public or private research centers.
L'archive ouverte pluridisciplinaire HAL, est destinée au dépôt et à la diffusion de documents scientifiques de niveau recherche, publiés ou non, émanant des établissements d'enseignement et de recherche français ou étrangers, des laboratoires publics ou privés. 


\title{
How do Reservation Prices Impact Distressed Debt Rescheduling ?
}

\author{
September, 2014
}

\section{Franck MORAUX ${ }^{1}$}

Université de Rennes 1 and CREM

\section{Patrick NAVATTE}

Université de Rennes 1 and CREM

\footnotetext{
${ }^{1}$ Authors acknowledge financial supports from Rennes Graduate School of Management and CREM - the Centre for Research in Economics and Management (CNRS research unit $\mathrm{n}^{\circ} 6211$ ). Corresponding author: Franck Moraux: Université de Rennes 1, Graduate School of Management, 11 rue Jean Macé, 35000 Rennes. Phone number:00 332-23-23-78-08. Fax number: 00 33-2-23-23-78-00, franck.moraux@univ-rennes.fr. Patrick Navatte: Université de Rennes 1, Graduate School of Management, 11 rue Jean Macé, 35000 Rennes. Phone number:00 332-23-23-78-04. Fax number:00 33-2-23-23-78-00, patrick.navatte@univ-rennes1.fr. Authors thank Eric de Bodt, Marie Brière, Patrice Fontaine and participants of CREM seminar for comments on an earlier version of this paper. The final version of this paper has greatly benefited from the exchange with an anonymous referee. We warmly thank him or her for comments.
} 


\title{
How Do Reservation Prices Impact Distressed Debt Rescheduling?
}

\begin{abstract}
This paper is the first to investigate rescheduling of distressed corporate debt when both the representative shareholder and the creditor face reservation prices. Parties expect from rescheduling both recovery and growth, but reservation prices are key dimensions to consider in the analysis in order to assess the opportunity and to design the new financial set-up. For reservation price, creditor may have in mind the liquidation value of the firm he can get by a strict enforcement of his contractual rights in court. The shareholder requires from rescheduling the recognition of her risky, specific and important (financial and intangible) involvements in the future. To shed lights on rescheduling with reservation prices, we develop first a general parsimonious distribution-free structural framework. We derive sufficient conditions for rescheduling to take place and highlight situations where no rescheduling can occur. We characterize cases where rescheduling is for the creditor possible but sub-optimal. So the shareholder's reservation price can dramatically restrict the set of possible extensions and it does matter for the creditor. We then restrict our setting to undertake numerical analysis, our benchmark being the canonical rescheduling model of Longstaff (1990). Here, we can explore with simulations feasibility and optimality of rescheduling for different magnitudes of reservation prices and different firm's profiles. We finally investigate various concerns related to rescheduling such as agency costs, exit from no-rescheduling situations and bargaining between stakeholders. We find and discuss different ways to lower the shareholder's reservation price.
\end{abstract}

Keywords: distressed debt, bankruptcy costs, debt rescheduling, reservation price, contingent claim analysis, business risk.

JEL classification: G 33 . 


\section{Introduction}

Rescheduling $^{2}$ is a popular way to reorganize capital structure and to renegotiate corporate debts in distress (Asquith, Gertner and Scharfstein (1994)). Both empirical evidences and anecdotic observations reveal that debt restructuring almost systematically involve rescheduling (cf. Gilson et al. (1990)). On principle, rescheduling is a mean to postpone existing financial demands and constraints. It can have however many other merits as shown by the rich corporate finance literature on the debt maturity design (see Fan et al. (2012) for a recent study). This is especially the case when the new maturity is cooperatively designed by both the debtor and the creditor, because we can expect both interests to be taken in account.

When dealing with distressed debts, avoidance of liquidation costs is commonly recognized as the first determinant to decide rescheduling (Micucci and Rossi (2010)). Longstaff (1990) notably develops a contingent claim analysis with liquidation costs. A piece of recent literature develops his canonical model further (see Harding and Sirmans (2002), Moraux and Navatte (2007), Chen et al. (2008) and Lee and Chung (2009)) $)^{3}$. In all these contributions, the creditor designs the rescheduling alone and he chooses the new debt maturity without facing special constraints. Consequently, it is sufficient for him to compare the price of the new rescheduled debt to the realization value he can get by seizing the distressed firm and liquidating the assets. In this vein of modeling, the representative shareholder appears surprisingly passive ${ }^{4}$. Of course, a strong argument for this passiveness is that she is better off in all rescheduling scenarios because her participation in the distressed firm is simply worth nothing.

\footnotetext{
${ }^{2}$ Throughout the paper, rescheduling and debt maturity extension are synonymous.

${ }^{3}$ Harding and Sirmans (2002), for instance, demonstrate in this setting that maturity extension aligns interests of borrowers and lenders better than renegotiation of principal and forgiveness do. And effectively, Franks and Sussman (2005) report only one case of debt forgiveness in their rich database made of 542 bank restructurings of small to medium size UK companies.

${ }^{4}$ A notable exception is Moraux and Navatte (2007) who remark that the shareholder-manager has strong incentives to change the risk profile of the firm before entering renegotiation.
} 
Analysis of existing literature reveals that all past contributions consider a unique reservation price: the liquidation value of the firm's assets for the creditor ${ }^{5}$. Other way saying, offering an epsilon to the shareholder is sufficient to make rescheduling possible. In the canonical framework, she has just no reservation price and is assumed to be essentially passive. Rescheduling is designed by the creditor as if he is "myopic" and "lazy", i.e. as if his decision just relies on a simple rule based on the liquidation value only. Of course, from a strict contractual viewpoint, considering passiveness and no reservation price for shareholders is completely correct. Once again, equity is worth nothing and, as recalled by Franks and Sussman (2005), the creditor "has an exclusive right to decide whether, when and how to seize the company's assets and liquidate them".

Reality is of course not that simple and some remarks deserve to be done. First of all, this somewhat mechanical view significantly contrasts with empirical findings. Franks and Sussman (2005), for instance, report that UK bankers behave far more subtly in the treatment of financial distress. They also find only mitigated results with respect to "lazy banking"6 Second, a too literal "contractualist" approach clearly excludes what is meant by "negotiation". In this sense, the canonical setting of Longstaff (1990) and followers where rescheduling is automatic and imposed by the creditor is outrageously asymmetric and in favor of this latter. Third, if rescheduling intervenes without consulting shareholders, then the traditional agency cost of Jensen and Meckling (1976) is certainly exacerbated. Nothing indeed prevents the so-called "passive" shareholder to act strategically after the "agreement" and, why not, at the creditor's expense. The creditor can then face ex post damaging changes of the business profile and/or some risk-shifting operation (see recent empirical evidences reported by Eisdorfer (2008) and Esmer (2013)). The bottom line of this is that the creditor may be worse not to involve the representative shareholder during the rescheduling design.

\footnotetext{
5 The "reservation price" perspective developed in this paper has neither been explicitly recognized elsewhere nor exploited in any mean by former contributions.

${ }^{6}$ For short we can retain four issues: a) "banks' typical response to distress is an attempt to rescue the firm (rather than liquidate it automatically)", b) "banks do not hurry to exercise their liquidation rights and engage in a fairly elaborate rescue process", c) "bank's decision to liquidate a firm is sensitive to the firm's own restructuring efforts, such as replacing its managers" and finally d) "banks show an interest in the going concern value of the firm and do not confine themselves to valuing the firm's collateral".
} 
The corporate finance perspective on the ongoing concern of the firm and the associated shareholder's behavior also questions the absence of such a reservation price. Observing that a shareholder has no reservation price is not good news for the creditor. This is equivalent to detecting that the shareholder has nothing to lose entering the deal ${ }^{7}$. By entering what resembles a gamble for resurrection, she will act accordingly and the creditor may face after the "renegotiation" an extreme version of the asset substitution effect as discussed in-depth in Décamps and Faure-Grimaud (1998, 2000). Existence of a reservation price means by contrast that the shareholder is ready not to accept any rescheduling. Some rescheduling are just too minor to be conducted. When reservation prices exist and rescheduling is decided, the creditor (resp. the representative shareholder) can be reassured on the willingness/interest of the representative shareholder (resp. the creditor) to support the recovery project. The creditor can in particular consider the representative shareholder has a positive view on the future perspectives of the firm. In this sense reservation prices may reveal some private analysis. With this in mind, it is clear that assuming a non-zero reservation price for the shareholder is not necessarily a bad news for restructuring, the targeted recovery and the creditor's wealth.

This paper is the first to develop a general distribution-free framework to analyze rescheduling of distressed corporate debt with reservation prices. It also extends the canonical setting of Longstaff (1990) to stress quantitative consequences of introducing a shareholder's reservation price. Our aim is to enrich the traditional view on rescheduling decision by introducing a reservation price for the representative shareholder and to investigate consequences on the debt maturity design. Of course, one may expect this "new" dimension to constrain, limit and prevent in some contexts corporate debt rescheduling. However, the precise quantitative effect of the reservation price remains difficult to intuit. First, the magnitude of the reservation price depends on the shareholders' preference that may be quite heterogeneous. Second, the magnitude of the reservation price may vary with the rescheduling design according to the shareholders' preference. The shareholder's decision

\footnotetext{
${ }^{7}$ Another issue, we do not elaborate further, concerns the affective value in the eyes of the shareholder. Some shareholders could really face some difficulties to up-date their "beliefs" on the firm by confronting figures to reality and accepting the close-to-zero dollar value of equity in case of severe distress. For more discussion on such a behavioural issue, one refers to Davis et al. (2011).
} 
is indeed to enter (or not) a restructuring activity with a specific time dimension. This activity is moreover costly and risky until it comes to a happy end. Consequently, it appears important to consider situations where reservation prices are constant or alternatively depend on the duration of the rescheduling period ${ }^{8}$. In all cases, we expect debt rescheduling to differ significantly from the standard setting that simply neglects shareholder's reservation price.

The reservation price we introduce is the minimum value the representative shareholder has in mind to obtain from restructuring. This price acts for her as a threshold that triggers the decision to enter or not the risky deal. It doesn't impact directly the value of the firm's assets but it can significantly influence the total value of the firm (which is the total value of the claims) once the rescheduling is decided, through the design of the new financial set-up. Nothing is therefore paid as an investment. The reservation price is just a useful benchmark to appreciate the new equity price. We can more concretely understand the reservation price as the present value of extra compensations required to reward or to attract for some specific talents or skills, such as for example a deep knowledge of the industry. Here, the reservation price is a virtual (rescheduling-dependent) "floor" dollar-compensation inciting to invest in a distressed firm with a specific saga. Accounting for a reservation price is also a way to bring into the model the value of other opportunities and exit options the shareholder can have in her portfolio. Finally, such a parameter can introduce a kind of behavioral dimension in a traditional contingent claim analysis ${ }^{9}$. Once a non-zero reservation price is taken into account, the post-restructuring value of equity is constrained to be more than epsilon. So, part of the shareholder's wealth is involved in the on-going business. Consequently, she is incited to commit herself to ensure recovery and success, far more reasonably and strategically than in the canonical setting. Once again, existence of a non-zero reservation price for the shareholder is not per se bad news for other stakeholders. This amount must be balanced with the talent and skills of the representative shareholders and the expected return, recovery and growth of the firm's assets.

This paper contributes to the literature by a) introducing reservation price of shareholders in the analysis of rescheduling, b) showing that and how reservation prices may

\footnotetext{
${ }^{8}$ We thank the referee for this idea.

${ }^{9}$ See footnote 7 .
} 
prevent alignment of interest between creditors and debtors, c) highlighting examples where rescheduling is actually feasible in an optimal way for creditors, just feasible or impossible to implement. In addition, we investigate potential exit solutions such as a change in the business model, introduce bargaining power of parties and resolve the associated asymmetric Nash bargaining game. Overall, the paper revisits the contingent claim analysis by considering (for the first time to the best of our knowledge) a couple of reservation prices in rescheduling. In simulations, we essentially capitalize on Longstaff (1990) and followers for benchmarking purposes ${ }^{10}$.

The rest of the paper is organized as follows. Section 2 presents our structural framework equipped with a reservation price for the representative shareholder and one for the creditor. Section 3 introduces (distribution-free) analytical results and consequences of such reservation prices. We expose there the constrained optimization problem the creditor is supposed to solve. Section 4 undertakes simulations. Section 5 discusses a number of additional issues such as the asset substitution problem and the possibility to design the optimal rescheduling as the solution of an asymmetric generalized Nash bargaining game. Section 6 provides empirical implications. Section 7 concludes.

\section{The structural framework and problem statement}

This section develops a parsimonious two-period setting to investigate rescheduling of distressed debt in presence of reservation prices. It must be stressed (and this will become clearer below) that the nature and the length of the two periods are not expected to be the same. The first one is given and deduced from the debt contract maturity, while the second one is endogenous and results from the design of rescheduling. It should be clear that a

\footnotetext{
${ }^{10}$ Our analysis partly benefits from the (contingent claim) analysis of Black and Scholes (1973) and Merton (1974), because the representative shareholder owns a call option written on the firm's assets. An important difference exists however because the expiration of the call is endogenous and chosen by the creditor. The call expiration actually solves a constrained optimization problem and, if possible, the creditor will choose the optimal investment horizon highlighted by Longstaff (1990). It is shown hereafter that this situation can occur only in special situations. In any case, some well known properties of the equity price do not hold anymore, because structural parameters can influence the endogenous horizon. Our aim in this investigation is to derive distribution free results. However we consider that the firm's asset value process can only diffuse after rescheduling meaning that it cannot jump... Diffusion processes introduce sufficient randomness in the analysis while avoiding dramatic problems when considering multiple threshold crossings in the reasoning.
} 
continuous time environment is preferable for modelling the optimal horizon on the second period.

Let it be a levered firm whose assets are currently worth $V_{0}$ and whose capital structure consists of equity and a single discount bond maturing at time $T_{1}$ and promising a face value $F_{1}$. The equity is held by a representative shareholder. At the end of the first period that is at time $T_{1}$, the firm can experience financial distress and rescheduling. The length of the second period is chosen by the creditor and eventually accepted by the representative shareholder. Financial markets contain riskless assets paying a constant interest rate denoted by $r$. Information is free and there is no tax, nor transaction costs, but there are some costs associated to the liquidation of bankrupt firms. Consequently, our setting is not perfect as per Modigliani and Miller (1958) and the total value of the firm is not equal to the firm's assets value. Rather, the total value of the firm is the firm's assets value net of imperfections that is minus the expected value of liquidation costs.

At the end of the first period (i.e. debt maturity $T_{1}$ ), the creditor effectively receives the face value $F_{1}$ if the firm's assets value is sufficient to cover the due payment $\left(V_{T_{1}} \geq F_{1}\right)$. Otherwise and in case of no rescheduling, he can only get the liquidation value of assets as recovery upon default. This value amounts to $\beta V_{T_{1}}$, where $\beta \in[0,1[$ is the realization rate of the firm's assets. $\beta V_{T_{1}}$ constitutes a natural reservation price for the creditor to assess the advantage of any restructuring decision in case of default. Liquidation costs (amounting to $(1-\beta) V_{T_{1}}$ here) give the creditor a clear incentive to restructure debt and extend the debt maturity.

To decide and design a maturity extension at time $T_{1}$ in case of default, the creditor rationally compares the continuation value of their debt to the reservation price. The continuation value of the debt is the value of the rescheduled debt $D\left(V_{T_{1}}, F_{1}, T_{2} ; \beta\right)$ assuming for a while that the new maturity $T_{2}$ is given. We denote by $\tau=T_{2}-T_{1}$ the associated time to maturity. The continuation value depends on liquidation costs because liquidation can still occur at time $T_{2}$. The reservation price for the creditor is equal to $\beta V_{T_{1}}$ (the realization value 
of the firm) because he can alternatively seize the firm and immediately liquidate the assets. Overall, the creditor's net gain function of rescheduling is given by

$$
\begin{aligned}
H_{\text {debt }}\left(V_{T_{1}}, F_{1}, T_{2} ; \beta\right) & =D\left(V_{T_{1}}, F_{1}, T_{2} ; \beta\right)-\beta V_{T_{1}} \\
& =\int e^{-r\left(T_{2}-T_{1}\right)}\left(\beta V_{T_{2}} 1_{V_{T_{2}}<F_{1}}+F_{1} 1_{V_{T_{2}} \geq F_{1}}\right) f\left(V_{T_{2}} \mid V_{T_{1}}\right) d V_{T_{2}}-\beta V_{T_{1}} \\
& =\int e^{-r\left(T_{2}-T_{1}\right)}\left(F_{1}-\beta V_{T_{2}}\right) 1_{V_{T_{2}} \geq F_{1}} f\left(V_{T_{2}} \mid V_{T_{1}}\right) d V_{T_{2}}
\end{aligned}
$$

where $1_{A}$ is the indicator function that is worth 1 if $\mathrm{A}$ is verified and 0 otherwise, $f\left(V_{T_{2}} \mid V_{T_{1}}\right)$ is the risk neutral distribution of the firm's assets value at time $T_{2}$ conditional on its value at time $T_{1}$. Note that the third equality applies because the discounted value of the firm's assets is a martingale under the risk neutral setting. The net gain function $H_{\text {debt }}\left(V_{T_{1}}, F_{1}, T_{2} ; \beta\right)$ can be positive, negative or null depending on structural parameters, on the rescheduling design (i.e., the choice of $T_{2}$ or $\tau$ ) and on the distribution of the firm's assets value. Of course, the creditor will extend the maturity of his debt (in distress) if and only if his net gain function is positive and by favoring, among possible horizons, the one offering the maximum net gain. The optimal rescheduling period for the creditor solves the following (unconstrained) optimization problem

$$
\arg \max _{\tau>0} H_{\text {debt }}\left(V_{T_{1}}, F_{1}, T_{1}+\tau ; \beta\right)
$$

where $\tau$ represents the length of time to new maturity. This is the traditional setting to investigate and understand rescheduling, where no constraint is placed on the set of possible horizons (see Longstaff (1990)). If ever the representative shareholder has no reservation price, rescheduling is automatically executed with an optimal duration denoted by $\tau_{L}^{*}(\beta)$. It is worth noting that, for virtually all interesting distributions for the time $T_{2}$-value of the firm's assets, the optimal horizon must be found numerically. Fortunately, the objective function $H_{\text {debt }}$ has nice properties among which a maximum value at horizon $\tau_{L}^{*}$ and a specific horizon denoted by $T_{\max }^{\mathrm{de}}$ (or by $T_{\max }^{\mathrm{de}}(\beta)$ if one wants to emphasize the dependence to liquidation costs) beyond which it is negative and strictly decreasing (with $\tau_{\max }^{\mathrm{de}}=T_{\max }^{\mathrm{de}}-T_{1}$ the 
associated duration $)^{11}$. One may denote by $W_{\text {debt }}\left(V_{T_{1}}, F_{1}, T_{2} ; \beta\right)=D\left(V_{T_{1}}, F_{1}, T_{2} ; \beta\right)$ the wealth of the creditor at rescheduling.

Now, consider that the representative shareholder has a reservation price and denote it generically by $K$. One will assume for a while that $K$ is constant and that the new maturity $T_{2}$ is given. The benchmark function used by the representative shareholder to assess rescheduling at time $T_{1}$ is defined by the wealth she can expect from rescheduling minus the reservation price she has in mind or more formally:

$$
H_{\text {eq }}\left(V_{T_{1}}, F_{1}, T_{2} ; K\right)=W_{\text {eq }}\left(V_{T_{1}}, F_{1}, T_{2}\right)-K=\int e^{-r\left(T_{2}-T_{1}\right)}\left(V_{T_{2}}-F_{1}\right) 1_{V_{T_{2}} \geq F_{1}} f\left(V_{T_{2}} ; V_{T_{1}}\right) d V_{T_{2}}-K,
$$

where the integral expression captures the expected value of the discounted wealth the representative shareholder can obtain at time $T_{2}$. For a given $T_{2}$, the time $T_{1}$-value of the shareholder's wealth is the time $T_{1}$-value of a call option written on the firm's assets ${ }^{12}$. Option theory (see for instance Merton (1973, theorem 1)) then tells us that wealth is strictly increasing with time to maturity $T_{2}-T_{1}$. We therefore expect the shareholder to be better off increasing the rescheduling horizon, unless the reservation price depends on the extra granted duration in a way that balances the effect of time (this kind of shareholder's preferences is discussed below). The benchmark function exposed in equation (3) can be positive, negative or null depending on structural parameters, on the rescheduling design (i.e. the choice of $T_{2}$ )

\footnotetext{
${ }^{11}$ Actually, the third equality of expressions (1) implies that the creditor's net gain function admits a maximum with respect to time to maturity. To understand this heuristically, remark that, for very near horizons $T_{2}$, a recovery of the firm is just impossible and the event $\left\{V_{T_{2}} \geq F_{1}\right\}$ is unlikely to occur so shortly after $T_{1}$. The function may be negative here depending on the process chosen for the firm's assets value and associated parameters. As the rescheduling horizon is considered later, the value of the objective function first increases until $\tau_{L}^{*}$ and then decreases before ending negative for longest horizons (beyond the horizon $T_{\max }^{\mathrm{de}}$ ). Consequently, there exists a maximum value for the creditor's objective function. To understand the decreasing feature beyond $\tau_{L}^{*}$, note that the creditor's wealth at maturity is ceiled by the face value $F_{1}$ and that the discount factor sharply decreases to zero as the time to maturity $T_{2}-T_{1}$ gets larger. So, the objective function, that balances the wealth to the constant realization value $-\beta V_{T_{1}}$, decreases for longer horizons. It even becomes negative for furthest horizons and tends to $-\beta V_{T_{1}}$. This is the case, for instance, in the canonical model of Longstaff (1990) and in the setting we develop in section 3.

${ }^{12}$ See footnote 9.
} 
and on the distribution of the firm's assets value. In any case, the representative shareholder can accept the restructuring only if the rescheduling horizon is large enough to ensure that the claim she receives (the new equity) is higher than the reservation price she has in mind, or equivalently only if her benchmark function is positive. The bottom line of this discussion is that the creditor must design a rescheduling that keeps the shareholder's benchmark function positive. He must therefore solve the constrained optimization problem given by

$$
\max _{\substack{\tau \geq 0 \\ H_{\mathrm{eq}}\left(V_{T_{1}}, F_{1}, T_{1}+\tau ; K\right)>0}} H_{\text {debt }}\left(V_{T_{1}}, F_{1}, T_{1}+\tau ; \beta\right) .
$$

To capture different shareholder's preferences, it is worth considering different specifications for the reservation price ${ }^{13}$. A constant reservation price will suit shareholders who are indifferent to the rescheduling duration. Otherwise, a reasonable reservation price is any strictly increasing function of the rescheduling duration, that is a any function having a positive first derivative with respect to the duration (or more formally $K^{\prime}(\tau)>0$ for any $\tau$ ) because the effort lasts longer as the rescheduling period gets larger. Among possible duration-dependent functions, the linear specification, $K(\tau)=k \tau$ with $k$ a positive real number, is a simple attractive candidate. Here the parameter $k$ models the reward for effort required by the representative shareholder (per unit of time ). Depending on the specification for the reservation price, the benchmark function may have different properties ${ }^{14}$. When associated to constant reservation prices, the benchmark function $H_{\mathrm{eq}}$ has necessarily negative values for shortest horizons $T_{2}$ (including $T_{1}$ ) and it increases as the duration increases. When associated to duration-dependent reservation prices, benchmark functions can have negative values for shortest horizons $T_{2}{ }^{15}$, and then everything is possible in broad generality because the sensitivity of the representative shareholder's wealth to duration is

\footnotetext{
${ }^{13}$ We thank an anonymous referee for suggesting this fruitful development.

${ }^{14}$ To avoid uninteresting situations, we will consider only reasonable values for the reservation price. In the following section, one will derive a number of sufficient conditions to highlight when rescheduling is feasible. But, for the moment, it is sufficient to require the constant reservation price to be lower than the time $T_{1}$ value of the firm (which is of course the maximum value the shareholder can expect) and to demand the reward for effort per unit of time to be lower than the slope of the line that is tangent to the equity value viewed as a function of the rescheduling duration.
}

15 depending on specification and excluding $T_{1}$ for linear specifications. 
balanced with the one of the reservation price. The most important point is that any benchmark function will decrease from a (more or less) long term horizon $T_{2}$. The reason for this is that the wealth of the shareholder is bounded by $V_{T_{1}}$, whereas the reservation price is a strictly increasing function of the duration $\tau$. As $T_{2}$ tends to infinity, the time $T_{1}$-value of the representative shareholder's wealth tends to $V_{T_{1}}$ while the reservation price (unless constant) remains unbounded. This is typically the case, for instance, for our linear candidate $K(\tau)=k \tau$. When the reservation price $K(\tau)$ is duration dependent, nothing special happens to the rescheduling design described by equation (4), the benchmark function of the representative shareholder is just modified accordingly. For a linear specification, one has $H_{\text {eq }}\left(V_{T_{1}}, F_{1}, T_{2} ; k\right)=W_{\text {eq }}\left(V_{T_{1}}, F_{1}, T_{2}\right)-k\left(T_{2}-T_{1}\right)$. Compared to a setting with a constant reservation price $K$, we can then expect rescheduling to be postponed, similar or hastened depending on whether $K(\tau)$ is greater, equal or smaller than $K$. For very short periods $\tau$, the reservation price $K(\tau)$ is of course very small and smaller than $K$ so that it is less constraining than it (and even not constraining at all). For moderate to long period of time, linear specification leads to interesting situations.

The aim of this paper is to shed light on the above constrained optimization problem and the associated set of possible rescheduling horizons. It is therefore worth introducing additional notations to qualify specific horizons. Let's denote, for a generic reservation price $K, \tau^{*}\left(V_{T_{1}}, K, \beta\right)$ the possible extension period if any that solves the constrained optimization program (4), $T^{*}=T_{1}+\tau^{*}$ the associated rescheduling horizon. $T_{\min }^{\mathrm{eq}}(K)$ is the soonest horizon after $T_{1}$ such that $H_{\mathrm{eq}}\left(V_{T_{1}}, F_{1}, T_{\min }^{\mathrm{eq}}(K) ; K\right)=0$ and, where appropriate, $T_{\max }^{\mathrm{eq}}(K)$ is the soonest horizon after $T_{\min }^{\mathrm{eq}}(K)$ nullifying the benchmark function. Of course, $\tau_{\min }^{\mathrm{eq}}(K)=T_{\min }^{\mathrm{eq}}(K)-T_{1}$ and $\tau_{\max }^{\mathrm{eq}}(K)=T_{\max }^{\mathrm{eq}}(K)-T_{1}$ represent associated time-to-maturities. Superscripts 'eq' insist here on the fact that values are driven by the shareholder's preference $(K)$. The formal definition of $\quad T_{\min }^{\mathrm{eq}}(K) \quad$ is $T_{\min }^{\text {eq }}(K)=\inf \left\{t>T_{1}: H_{\text {eq }}\left(V_{T_{1}}, F_{1}, t ; K\right)=0\right\}=\inf \left\{t>T_{1}: W_{\text {eq }}\left(V_{T_{1}}, F_{1}, t\right)=K\right\} \quad$ (for $\quad$ a $\quad$ generic 
reservation price $K)$. Depending on the specification of $K$, this value is more or less difficult to figure out.

Before ending this section, it is also worth discussing very first properties of these horizons under the two possible specifications of the reservation price. For constant reservation prices $K$, there exists only one maturity such that the value of the shareholder's wealth is exactly worth the reservation price. And this in turn has a couple of consequences. First of all, $T_{\max }^{\mathrm{eq}}(K)$ does not exist. Second, a particular reservation price may be associated to any rescheduling horizon $T$ chosen by the creditor. This reservation price is special because it is the largest one compatible with such a rescheduling horizon. One may therefore denote it by $K_{\max }^{\mathrm{de}}(T)$ where the superscript 'de' insists on the fact that the computation is driven by the creditor's preference $(T) . \quad K_{\max }^{\text {de }}(T)$ is then unambiguously defined by $H_{\text {eq }}\left(V_{T_{1}}, F_{1}, T ; K_{\max }^{\text {de }}(T)\right)=0$ or equivalently $K_{\max }^{\text {de }}(T)=W_{\text {eq }}\left(V_{T_{1}}, F_{1}, T\right)$. Interestingly, for a given reservation price $K$, the creditor will (or not) be able to find an optimal rescheduling horizon $T^{*}\left(V_{T_{1}}, K, \beta\right)$. In case he can, we can look for the largest reservation price compatible with such a choice. Let's denote it by $K^{*}(K)$. This function of $K$ solves $H_{\mathrm{eq}}\left(V_{T_{1}}, F_{1}, T^{*}\left(V_{T_{1}}, K, \beta\right), K^{*}(K)\right)=0$ and one has $K^{*}(K)=K_{\max }^{\mathrm{de}}\left(T^{*}\left(V_{T_{1}}, K, \beta\right)\right)$ where no superscript is obvious because preferences are blended. Linear reservation prices provide interesting settings to consider. The role of the rescheduling duration indeed becomes rather subtle, because the maximum possible horizon for the representative shareholder (if any) is $T_{\max }^{\mathrm{eq}}$ - the largest values of the two solutions of $H_{\mathrm{eq}}\left(V_{T_{1}}, F_{1}, t ; k t\right)=0$. Moreover, when reservation prices depend on the duration to optimize, they are no longer exogenous but treated as an element of the problem.

\section{Analyzing distressed debt rescheduling in presence of reservation prices}

This section derives distribution-free results. The rescheduling maturity we consider solves the constrained optimization problem defined by equation (4) and is therefore endogenous. Consequently, analytical results may deviate from what can be expected from 
the standard contingent claim analysis. Note that, for checking, we set the shareholder's reservation price to zero in order to verify whether properties first highlighted by Longstaff (1990) are recovered.

To begin this section, we sum up in proposition 1 the very first analytical pricing implications of the above distribution-free setting. Notice that we assume here that a rescheduling is possible. The rest of the section then highlights conditions under which restructuring is feasible and when and how reservation prices impact rescheduling.

Proposition 1: If rescheduling is possible at time $T_{1}$, then new equity and debt are respectively worth

$$
E q\left(V_{T_{1}}, F_{1}, \tau^{*}\left(V_{T_{1}}, K, \beta\right), K\right)=H_{\mathrm{eq}}\left(V_{T_{1}}, F_{1}, \tau^{*}\left(V_{T_{1}}, K, \beta\right) ; K\right)+K
$$

and

$$
D\left(V_{T_{1}}, F_{1}, \tau^{*}\left(V_{T_{1}}, K, \beta\right) ; \beta\right)=\mathrm{H}_{\text {debt }}\left(V_{T_{1}}, F_{1}, \tau^{*}\left(V_{T_{1}}, K, \beta\right) ; \beta\right)+\beta V_{T_{1}}
$$

where $\tau^{*}\left(V_{T_{1}}, K, \beta\right)$ solves the equation (4) and $K$ is the (generic) shareholder's reservation price $^{16}$. The total value of the firm is the sum of both and it equals

$$
\begin{aligned}
v\left(V_{T_{1}}, F_{1}, \tau^{*}\left(V_{T_{1}}, K, \beta\right) ; K, \beta\right) & =V_{T_{1}}-(1-\beta) \int e^{-r\left(\tau^{*}\left(V_{T_{1}}, K, \beta\right)-T_{1}\right)} V_{\tau^{*}\left(V_{T_{1}}, K, \beta\right)} 1_{V_{\tau^{*}}\left(V_{T_{1}}, K, \beta\right)}<F_{1} f\left(V_{\tau^{*}\left(V_{T_{1}}, K, \beta\right)} ; V_{T_{1}}\right) d V_{\tau^{*}\left(V_{T_{1}}, K, \beta\right)} \\
& =V_{T_{1}}-(1-\beta) V_{T_{1}} \mathrm{Q}\left[V_{\tau^{*}\left(V_{T_{1}}, K, \beta\right)}<F_{1}\right] \\
& =\beta V_{T_{1}}+(1-\beta) V_{T_{1}} \mathrm{Q}\left[V_{\tau^{*}\left(V_{T_{1}}, K, \beta\right)}>F_{1}\right]
\end{aligned}
$$

where Q stands for the proper probability.

Pricing formulae of proposition 1 are not as straightforward as they may seem at first sight because the maturity $\tau^{*}\left(V_{T_{1}}, K, \beta\right)$ - if any, solves the constrained optimization problem (4). Equalities related to the total value of the firm emphasize in different ways that rescheduling postpones potential liquidation costs firms to new horizon $T^{*}\left(V_{T_{1}}, K, \beta\right)$. The last expression suggests for instance that the total firm's value will be a strictly increasing function of the

\footnotetext{
${ }^{16}$ The equity price is a function of $K$ only through the design of the rescheduling horizon, so formally one could simplify the notation to $E q\left(V_{T_{1}}, F_{1}, \tau^{*}\left(V_{T_{1}}, K, \beta\right)\right)$.
} 
rescheduling period for most dynamics we can consider for the firm's assets value. Granting an extra period of time in standard frameworks just gives the firm more chance to recover.

Proposition 2: A necessary condition for rescheduling to occur at horizon $T$ is that the generic reservation price $K$ and the rescheduling horizon $T$ verify

$K<(1-\beta) V_{T_{1}} \mathrm{Q}\left[V_{T} \geq F_{1}\right]$.

Proposition 2 states that if the generic shareholder's reservation price is larger than the time$T_{1}$ value of liquidation costs that can be saved by offering a recovery option to the firm, then no rescheduling can occur. Hence, while liquidation costs at time $T_{1}\left((1-\beta) V_{T_{1}}\right)$ constitute a key determinant for the creditor to decide rescheduling, the time- $T_{1}$ value of saved liquidation costs constitutes a key determinant for stakeholders to decide rescheduling. Proposition 2 places a bound on constant reservation prices and on slopes of linear specifications when a rescheduling horizon is known and, alternatively, it places a bound on the rescheduling horizon when the constant reservation price or the slope of linear specification is known. As a warning, it must be emphasized that proposition 2 states a necessary condition for rescheduling not a sufficient one and that it does not say anything on whether the horizon $T$ is the optimal one to consider.

Proof: If rescheduling is possible with maturity $T$, then both the net gain function of the creditor and the benchmark function of the representative shareholder are simultaneously positive so that $D\left(V_{T_{1}}, F_{1}, \tau ; \beta\right)>\beta V_{T_{1}}$ and $E q\left(V_{T_{1}}, F_{1}, \tau ; K\right)>K$ where $\tau=T-T_{1}$. Now, summing expressions implies that the total value of the firm is necessarily larger than $\beta V_{T_{1}}+K$ or more formally $v\left(V_{T_{1}}, F_{1}, \tau ; K, \beta\right)>\beta V_{T_{1}}+K$. Then, plugging the third equality of Proposition 1 gives $\beta V_{T_{1}}+(1-\beta) V_{T_{1}} \mathrm{Q}\left[V_{T}>F\right]>\beta V_{T_{1}}+K$ and the result follows by simplification. 
Corollary : Existence of a shareholder's reservation price makes acceptance of rescheduling by both parties a good signal for the ongoing firm and environment. In that case, rescheduling is socially better than liquidation.

Proof: The proof of proposition 2 reveals that if rescheduling occurs then $v\left(V_{T_{1}}, F_{1}, T_{1}, \tau\right)>\beta V_{T_{1}}+K$ and therefore $v\left(V_{T_{1}}, F_{1}, T_{1}, \tau\right)>\beta V_{T_{1}}$.

The proposition 2 states a necessary condition for rescheduling, not a sufficient one (this is therefore true for the corollary too). $K<(1-\beta) V_{T_{1}} \mathrm{Q}\left[V_{T} \geq F_{1}\right]$ and social welfare $\left(v\left(V_{T_{1}}, F_{1}, T_{1}, \tau\right)>\beta V_{T_{1}}\right)$ do not suffice for rescheduling to occur. There exist situations where no rescheduling can intervene, because conditions do not ensure that both parties are better off. Restructuring may take place at the expense of one party.

The following proposition presents situations under which rescheduling (only) is not an appropriate solution.

Proposition 3: For a generic reservation price $K$, rescheduling is impossible to undertake if $T_{\max }^{\text {de }}(\beta)<T_{\min }^{\mathrm{eq}}(K)$.

Proof: We know from section 2 that there exists a largest horizon $T_{\max }^{\mathrm{de}}$ beyond which the creditor's net gain function is negative and the rescheduling impossible. If ever $T_{\max }^{\mathrm{de}}<T_{\min }^{\mathrm{eq}}(K)$ (for a generic $K$ ), then there is no way to satisfy both preferences.

This proposition shows that a failure to reschedule is possible because preferences (which are functions $\beta$ and the generic $K$ ) may be irreconcilable.

Corollary: In case the representative shareholder has a constant reservation price $K$, rescheduling is impossible to undertake if the reservation price verifies 
$K>K_{\max }^{\mathrm{de}}=K_{\max }^{\mathrm{de}}\left(T_{\max }^{\mathrm{de}}(\beta)\right)$. In case the representative shareholder has a linear reservation price $K(\tau)=k \tau$, rescheduling is impossible to undertake if the required reward for effort per unit of time verifies $k>k_{\max }^{\mathrm{de}}=\frac{K_{\max }^{\mathrm{de}}\left(T_{\max }^{\mathrm{de}}(\beta)\right)}{T_{\max }^{\mathrm{de}}(\beta)}$.

Proof: When the representative shareholder has a constant reservation price $K$, we also know from section 2 that there exists a maximum reservation price $K_{\max }^{\mathrm{de}}(T)$ associated to any rescheduling horizon $T$. This in turn yields $K_{\max }^{\mathrm{de}}\left(T_{\max }^{\mathrm{de}}\right)=W\left(V_{T_{1}}, F_{1}, T_{\max }^{\mathrm{de}}\right) \equiv K_{\max }^{\mathrm{de}}$. Note that, because the wealth function is a strictly increasing function of $T$, it is a one-to-one function on appropriate intervals. And, because $K$ is constant, $K>W_{\text {eq }}\left(V_{T_{1}}, F_{1}, T_{\text {max }}^{\text {de }}\right)$ leads to $W_{\text {eq }}^{-1}\left(V_{T_{1}}, F_{1}, K\right)>T_{\max }^{\text {de }}$ where $W_{\text {eq }}^{-1}\left(V_{T_{1}}, F_{1}, K\right)$ returns the minimum horizon that fixes the constraint. When the representative shareholder has a linear reservation price $K$, then the larger the slope, the longer the duration required by the shareholder. And the maximum slope admissible with $T_{\max }^{\mathrm{de}}(\beta)$ verifies $k_{\max }^{\mathrm{de}} T_{\max }^{\mathrm{de}}(\beta)=W\left(V_{T_{1}}, F_{1}, T_{\max }^{\mathrm{de}}\right)$

The next proposition highlights, in the case of constant reservation price, conditions under which rescheduling is optimal and conditions under which it is feasible although not completely optimal. To begin with, it is necessary to reconsider the creditor's optimization problem and then to shed more light on $K^{*}(K)$ the function introduced in section 2 that, for a given level of reservation price, gives the maximum reservation prices the creditor's rescheduling decision can face. In section 2 , it is defined by $K^{*}(K)=K_{\max }^{\mathrm{de}}\left(T^{*}\left(V_{T_{1}}, K, \beta\right)\right)$.

Lemma: Consider a representative shareholder with a constant reservation price $K$ lower than $K_{\max }^{\mathrm{de}}$. Then, the rescheduling duration is given by $\tau^{*}\left(V_{T_{1}}, K, \beta\right)=\max \left(\tau_{\min }^{\mathrm{eq}}(K), \tau^{*}\left(V_{T_{1}}, 0, \beta\right)\right)=\max \left(\tau_{\min }^{\mathrm{eq}}(K), \tau_{L}^{*}(\beta)\right) \quad$ with $\tau_{L}^{*}(\beta)$ the optimal solution of the unconstrained problem (2) or more explicitly: 
$\tau^{*}\left(V_{T_{1}}, K, \beta\right)=\left\{\begin{array}{cc}\tau_{L}^{*}(\beta) & \text { if } \\ \tau_{\text {min }}^{\mathrm{eq}}(K) & \text { otherwise }\end{array} \quad K \leq W_{\mathrm{eq}}\left(V_{T_{1}}, F_{1}, T_{L}^{*}(\beta)\right)\right.$.

Proof: When the constant reservation price is not constraining, the rescheduling duration the creditor chooses is simply his first-best choice $\tau_{L}^{*}(\beta)$ which corresponds to the optimal solution of the unconstrained optimization problem (2). When the constant reservation price is constraining (meaning that he cannot enjoy the maximum value of his net gain function), he has no incentive to postpone maturity beyond the horizon that exactly fixes the shareholder's reservation price (he chooses $\tau_{\min }^{\mathrm{eq}}(K)$ ), because his net gain function is strictly decreasing beyond $\tau_{L}^{*}(\beta)$. It is clear that the value $W_{\text {eq }}\left(V_{T_{1}}, F_{1}, T_{L}^{*}(\beta)\right)$ acts as a threshold reservation price.

Lemma: The function $K^{*}(K)$ is given by $K^{*}(K)=W_{\mathrm{eq}}\left(V_{T_{1}}, F_{1}, T^{*}\left(V_{T_{1}}, K, \beta\right)\right)$ or more explicitly by

$$
K^{*}(K)=\left\{\begin{array}{ccc}
W_{\mathrm{eq}}\left(V_{T_{1}}, F_{1}, T_{L}^{*}(\beta)\right) & \text { if } & K \leq W_{\mathrm{eq}}\left(V_{T_{1}}, F_{1}, T_{L}^{*}(\beta)\right)=K^{*}(K) \\
K & \text { if } \quad W_{\mathrm{eq}}\left(V_{T_{1}}, F_{1}, T_{L}^{*}(\beta)\right)<K<K_{\max }^{\text {de }}
\end{array} .\right.
$$

Proof: The function $K^{*}(K)$ is the maximum reservation price the representative shareholder could have had given that the creditor has chosen $T^{*}\left(V_{T_{1}}, K, \beta\right)$. For any $K$ lower than $W_{\text {eq }}\left(V_{T_{1}}, F_{1}, T_{L}^{*}(\beta)\right)$, the reservation price is not binding and the unconstrained solution of the optimization problem applies. So the creditor chooses and implements the rescheduling duration $\tau_{L}^{*}(\beta)$ and, consequently, $K^{*}(K)=W_{\text {eq }}\left(V_{T_{1}}, F_{1}, T_{L}^{*}(\beta)\right)$. Interestingly, $K^{*}(K)$ does not depend on $K$ for reservation prices lower than the threshold $W_{\text {eq }}\left(V_{T_{1}}, F_{1}, T_{L}^{*}(\beta)\right)$. Now, for any $K$ lying between $W_{\mathrm{eq}}\left(V_{T_{1}}, F_{1}, T_{L}^{*}(\beta)\right)$ and $K_{\max }^{\mathrm{de}}=W_{\mathrm{eq}}\left(V_{T_{1}}, F_{1}, T_{\max }^{\mathrm{de}}\right)$, one has $K^{*}(K)=K$ because, by virtue of the previous lemma, the creditor chooses $\tau_{\min }^{\text {eq }}(K)$ as a second-best meaning that the representative shareholder cannot obtain more that $K$. Of course, the first 
result i) of proposition 3 states that rescheduling is impossible for any $K$ beyond $K_{\max }^{\mathrm{de}}$, so the function is not defined beyond this point.

Proposition 4: Consider a representative shareholder with a constant reservation price $K$ lower than $K_{\max }^{\mathrm{de}}$. Then, the rescheduling duration is given by $\tau^{*}\left(V_{T_{1}}, K, \beta\right)=\max \left(\tau_{\min }^{\mathrm{eq}}(K), \tau^{*}\left(V_{T_{1}}, 0, \beta\right)\right)=\max \left(\tau_{\min }^{\mathrm{eq}}(K), \tau_{L}^{*}(\beta)\right) \quad$ with $\tau_{L}^{*}(\beta)$ the optimal solution of the unconstrained problem (2) and furthermore a couple of scenarios emerge:

- If $K<K^{*}(K)$, then $\tau^{*}\left(V_{T_{1}}, K, \beta\right)=\tau_{L}^{*}(\beta)$, the rescheduling design is optimal for the creditor whose wealth is $W_{d e}\left(V_{T_{1}}, F_{1}, T_{L}^{*}(\beta) ; \beta\right)$ and the wealth of the representative shareholder amounts to $W_{\mathrm{eq}}\left(V_{T_{1}}, F_{1}, T_{L}^{*}(\beta)\right)$ which is strictly larger than her reservation price, the "surplus" amounting to $W_{\mathrm{eq}}\left(V_{T_{1}}, F_{1}, T_{L}^{*}(\beta)\right)-K$.

- If $K^{*}(K)<K<K_{\max }$, then $\tau^{*}\left(V_{T_{1}}, K, \beta\right)=\tau_{\min }^{\mathrm{eq}}(K)$ and rescheduling is just feasible but suboptimal for the creditor. The creditor is better off considering $T_{\min }^{\mathrm{eq}}(K)$ as rescheduling horizon and all pricing formulae of proposition 1 apply (except that of course $\tau_{\min }^{\mathrm{eq}}(K)$ replaces $\tau^{*}\left(V_{T_{1}}, K, \beta\right)$ ). In that case, the shareholder's wealth exactly covers her reservation price $\left(W_{\mathrm{eq}}\left(V_{T_{1}}, F_{1}, T_{\min }^{\mathrm{eq}}(K)\right)=K\right)$ and the reservation price has a negative impact on the creditor's wealth and the opportunity cost amounts to $\operatorname{Debt}\left(V_{T_{1}}, F_{1}, \tau_{L}^{*}(\beta)\right)-\operatorname{Debt}\left(V_{T_{1}}, F_{1}, \tau_{\text {min }}^{\text {eq }}(K)\right)$.

Proof: The function is $K^{*}(K)=K_{\max }^{\mathrm{de}}\left(T^{*}\left(V_{T_{1}}, K, \beta\right)\right)$ and it is the maximum reservation price the representative shareholder can have, given that the creditor chooses $T^{*}\left(V_{T_{1}}, K, \beta\right)$. It should be emphasized that for any $K$ lower than $K^{*}(K)=W\left(V_{T_{1}}, F_{1}, T_{L}^{*}\right)$ (which does not depend on $K)$, one has $K^{*}(K)=W\left(V_{T_{1}}, F_{1}, T_{L}^{*}\right)$. Now, for any $K$ lying between $K^{*}(K)$ and $K_{\max }^{\mathrm{de}}=W\left(V_{T_{1}}, F_{1}, T_{\max }^{\mathrm{de}}\right), \quad$ one has $K^{*}(K)=W\left(V_{T_{1}}, F_{1}, T_{\max }^{\mathrm{de}}(K)\right)$. Consequently, when 
$K^{*}(K)<K<K_{\max }$, then $\tau^{*}\left(V_{T_{1}}, K, \beta\right)=\tau_{\min }^{\mathrm{eq}}(K)$ and it is still worth for the creditor to extend the distressed debt maturity. The third point iii) suggests the creditor to view the impact of reservation price as some opportunity costs. Actually, there is no incentive for him to grant more delay, otherwise surplus benefits to the shareholder.

The next proposition is dedicated to linear reservation prices. If we know from Proposition 2 that there exist some values that make rescheduling impossible, this proposition specifies situations where only second-best rescheduling designs are possible and situations where no rescheduling can occur. Proposition 5 parallels but differs from Proposition 4 in various aspects. First, it is clearly related to Proposition 3 as it exhaustively enumerates all possible scenarios by the same way. Second, it heavily relies on the fact that the two parameters $\beta$ and $k$ (that respectively influence and capture stakeholders' preferences) can have unrelated values. The novelty here is that (at least in principle) the optimal horizon desirable for the creditor may be too far for the shareholder's time preference.

Proposition 5: Consider a representative shareholder with a linear reservation price $K(\tau)$ such that $T_{\min }^{\mathrm{eq}}(k)$ and $T_{\max }^{\mathrm{eq}}(k)$ exist. Then one of the following scenarios emerges.

- If $T_{\min }^{\mathrm{eq}}(k)<T_{\max }^{\mathrm{eq}}(k)<T_{L}^{*}(\beta)$, then $\tau^{*}\left(V_{T_{1}}, K, \beta\right)=\tau_{\max }^{\mathrm{eq}}(k)$. The rescheduling design is feasible but sub-optimal for the creditor. The creditor is better off considering $T_{\max }^{\mathrm{eq}}(k)$ as rescheduling horizon and all pricing formulae of proposition 1 apply (except that of course $\tau_{\max }^{\mathrm{eq}}(k)$ replaces $\tau^{*}\left(V_{T_{1}}, K, \beta\right)$ ). In that case, the shareholder's wealth in rescheduling just covers her reservation price $\left(W_{\mathrm{eq}}\left(V_{T_{1}}, F_{1}, T_{\max }^{\mathrm{eq}}\right)=k \tau_{\max }^{\mathrm{eq}}\right)$. There is no "surplus" for the representative shareholder and her reservation price has a negative impact on the creditor's wealth. The opportunity cost amounts to $\operatorname{Debt}\left(V_{T_{1}}, F_{1}, \tau_{L}^{*}\right)-\operatorname{Debt}\left(V_{T_{1}}, F_{1}, \tau_{\max }^{\mathrm{eq}}(k)\right)$. 
- If $T_{\min }^{\mathrm{eq}}(k)<T_{L}^{*}(\beta)<T_{\max }^{\mathrm{eq}}(k)$, then $\tau^{*}\left(V_{T_{1}}, K, \beta\right)=\tau_{L}^{*}(\beta)$. The rescheduling design is optimal for the creditor and the wealth of the representative shareholder amounts to $W_{\text {eq }}\left(V_{T_{1}}, F_{1}, T_{L}^{*}\right)$ which is strictly larger than her reservation price. The "surplus" is $W_{\text {eq }}\left(V_{T_{1}}, F_{1}, T_{L}^{*}\right)-k \tau_{L}^{*}$

- If $T_{L}^{*}(\beta)<T_{\min }^{\mathrm{eq}}(k)<T_{\max }^{\mathrm{de}}(\beta)$, then $\tau^{*}\left(V_{T_{1}}, K, \beta\right)=\tau_{\min }^{\mathrm{eq}}(k)$ and rescheduling is feasible but suboptimal for the creditor. The creditor is better off considering $T_{\min }^{\mathrm{eq}}(k)$ as rescheduling horizon and all pricing formulae of proposition 1 apply (except that of course $\tau_{\min }^{\mathrm{eq}}(k)$ replaces $\left.\tau^{*}\left(V_{T_{1}}, K, \beta\right)\right)$. In that case, the shareholder's wealth in rescheduling just covers her reservation price $\left(W_{\mathrm{eq}}\left(V_{T_{1}}, F_{1}, T_{\min }^{\mathrm{eq}}(k)\right)=k \tau_{\min }^{\mathrm{eq}}(k)\right)$. There is no "surplus" for the representative shareholder and her reservation price has a negative impact on the creditor's wealth. The opportunity cost amounts to $\operatorname{Debt}\left(V_{T_{1}}, F_{1}, \tau_{L}^{*}\right)-\operatorname{Debt}\left(V_{T_{1}}, F_{1}, \tau_{\min }^{\mathrm{eq}}(k)\right)$.

- If $T_{\max }^{\mathrm{de}}(\beta)<T_{\min }^{\mathrm{eq}}(k)$, then rescheduling is impossible.

In case there exists only one horizon $T^{\mathrm{eq}}$ such that $H_{\mathrm{eq}}\left(V_{T_{1}}, F_{1}, T^{\mathrm{eq}} ; K\right)=0$ (we have essentially $\left.T^{\mathrm{eq}}=T_{\max }^{\mathrm{eq}}(k)=T_{\min }^{\mathrm{eq}}(k)\right)$, the condition for rescheduling to exist is that $T^{\mathrm{eq}}$ and $T_{L}^{*}$ are similar or more formally that $\tau^{*}\left(V_{T_{1}}, K, \beta\right)=\tau_{L}^{*}(\beta) 1_{\left\{\tau^{\mathrm{cq}}=\tau_{L}^{*}(\beta)\right\}}$.

Proof: Scenarios depict possible situations exhaustively. All of them can exist, because values of parameters $\beta$ and $k$ admit no special relation in our setting.

Before ending this section, it is worth questioning whether results of Longstaff (1990) are recovered when $K$ is set to zero. Proposition 2 is still verified because the contemporaneous value of liquidation costs you can expect to save is strictly positive in all cases. Let's now turn to Proposition 4 (resp. Proposition 5), it is sufficient to remark that $T_{\min }^{\text {eq }}(K)$ drops to zero when $K$ (resp. $k$ ) is zero. This prevents both sub-optimal designs and 
impossibility result. Consequently, Longstaff (1990) solves the unconstrained optimization program (2) and focuses on $\tau\left(V_{T_{1}}, 0, \beta\right)$ only but $\tau\left(V_{T_{1}}, 0, \beta\right)=\tau^{*}\left(V_{T_{1}}, 0, \beta\right)=\tau_{L}^{*}$. In this vein of reasoning, the largest reservation price compatible with Longstaff (1990) optimal rescheduling is $K_{\max }\left(T_{L}^{*}\right)=K_{\max , L}^{*}$. The next section proposes simulations and from now on we consider and extend the canonical framework of Longstaff (1990).

\section{Simulations}

This section makes simulations to gain intuitions (both graphically and numerically) about theoretical results of section 3. Because the length of the second period of our setting is chosen by the creditor (it is variable and endogenous), a continuous time framework is needed to describe the firm's assets value dynamics at any possible rescheduling horizon. To keep things comparable with existing research, we use for the firm's assets value the risk neutral value process considered by Longstaff (1990) and followers and we assume that increments over a small period of time $d t$ are well described by

$d V_{t}=r V_{t} d t+\sigma V_{t} d W_{t}$

where $W=\left(W_{t}\right)_{t}$ is a standard Brownian motion and $\sigma$ stands for the firm's assets volatility ${ }^{17}$. Structural parameters we consider for simulations are consistent with previous studies. In Table 1 for instance, our base case parameters are $V_{T_{1}}=34, F_{1}=40, \sigma=20 \%$, $r=6 \%$. The realization rate $\beta$, that drives the creditor's reservation price, can typically take

${ }^{17}$ This dynamics implies that log-returns of the firm's assets are normally distributed, but our conclusions do not change for other kinds of distributions. Notice that, if the new extended horizon $T_{2}$ was arbitrarily and exogenously fixed by the creditor, then the pricing of corporate equity and debt after rescheduling would be straightforward. For a new horizon $T_{2}$, indeed, the net gain function of creditors is given by $H_{\text {debt }}\left(V_{T_{1}}, F_{1}, T_{2} ; \beta\right)=F_{1} e^{-r\left(T_{2}-T_{1}\right)} N\left\lfloor d_{2, V_{T_{1}} / F_{1}}\left(T_{2}-T_{1}\right)\right\rfloor-\beta V_{T_{1}} N\left\lfloor d_{1, V_{T_{1}} / F_{1}}\left(T_{2}-T_{1}\right)\right\rfloor \quad$ where $N[$.$] \quad is the$ standard cumulative density function, $d_{1, x}(t)=\frac{\ln x+\left(r+\frac{1}{2} \sigma^{2}\right) t}{\sigma \sqrt{t}}$ and $d_{2, x}(t)=d_{1, x}(t)-\sigma \sqrt{t}$. Moreover, the representative shareholder's one then $H_{\text {equity }}\left(V_{T_{1}}, F_{1}, T_{2} ; K\right)=\beta V_{T_{1}} N\left[d_{1, V_{T_{1}} / F_{1}}\left(T_{2}-T_{1}\right)\right]-F_{1} e^{-r\left(T_{2}-T_{1}\right)} N\left\lfloor d_{2, V_{T_{1}} / F_{1}}\left(T_{2}-T_{1}\right)\right]-K$. However, things are not that simple because the new horizon is endogenously given. Finally, it is interesting to note that the pricing probability in Proposition 1 is $\mathrm{Q}\left\lfloor V_{\tau^{*}\left(V_{T_{1}}, K, \beta\right)}>F_{1}\right\rfloor=N\left\lfloor d_{1, V_{T_{1}} / F_{1}}\left(\tau^{*}\left(V_{T_{1}}, K, \beta\right)\right)\right]$. 
different values. There are chosen so as to emphasize a specific feature and/or lines with recent empirical findings. Note that Andrade and Kaplan (1998) evidence that bankrupted firms lost between $10 \%$ and $23 \%$ of their value upon declaring bankruptcy (on a sample of 31 leveraged buyout firms that subsequently become financially distressed). In Bris et al. (2006), bankruptcy costs rise up to $20 \%$. Two banks give to Franks and Sussman (2005) total proceeds concerning 542 small and medium UK companies and computations lead to median costs equal to $26.8 \%$ and $18.5 \%$ respectively.

Figure 1 puts together four graphs that help to understand stakeholders' preferences with different reservation prices. The upper left graph displays the creditor's net gain function $H_{\text {debt }}$ as a function of the extra period $\tau=T-T_{1}$. The upper right graph displays the shareholder's benchmark function $H_{\mathrm{eq}}$ as a function of the extra period $\tau=T-T_{1}$ for some constant reservation prices, while the lower left graph does the same for three different linear reservation prices. The lower right graph represents the function $K^{*}(K)$ that plays an important role in Proposition 4. In the left upper graph, we set liquidation costs to fairly large values ( $\beta=40 \%$ and $\beta^{\prime}=20 \%$ ) for illustrative purposes. We can verify there that the net gain function is concave (as claimed in section 2), that it is maximum when the extra period is equal to $\tau_{L}^{*}(\beta)$ and that it is zero for $\tau_{\max }^{\mathrm{de}}(\beta)$. The graph also indicates how the net gain function increases when liquidation costs enlarge (i.e. when $\beta$ decreases). In absence of shareholder's reservation price, results of Longstaff (1990) apply and the creditor should rationally choose $\tau_{L}^{*}(\beta)$ as rescheduling horizon. Due to the shareholder's reservation price, this is not necessary possible in our extended framework. The upper right graph displays the shareholder's benchmark function $H_{\mathrm{eq}}$ as a function of the extra period $\tau=T-T_{1}$ for a couple of constant reservation prices $K=7$ and $K^{\prime}=1.5 \times K=10.5$. One may verify here the strict monotony of the shareholder's benchmark function with respect to the extra period of time. As expected, it is an increasing function of the extra period of time. The lower left graph plots as a function of the extra period $\tau=T-T_{1}$ three different shareholder's 
benchmark functions $H_{\mathrm{eq}}$ involving different linear reservation prices. For modeling different rewards for effort, we set $k=0.85, k^{\prime}=1.095 k$ and $k^{\prime \prime}=1.2 k$ (given that the larger the slope, the more constraining the shareholder's time-preference). This lower left graph well illustrates that the time-preference of the shareholder (captured by $k$ ) is a key dimension to consider. Depending of the required reward for effort, the benchmark function $H_{\text {eq }}$ may be positive only for rescheduling horizons chosen between $T_{\min }^{\mathrm{eq}}(k) T_{\max }^{\mathrm{eq}}(k)$, it may be (at best) equal to zero for a specific rescheduling horizon we denote by $T^{*}(k)$ or it may be never positive. Other way saying, the value of the equity held by the shareholder's in the rescheduled financial set-up may be larger than, just equal or lower than her reservation price. The lower right graph finally represents the function $K^{*}(K)$ that plays an important role in Proposition 4. It shows the maximum (constant) reservation price the shareholder can have for the rescheduling period chosen by the creditor in accordance to a level of reservation price $K$. For reservation prices $K$ lower than $W_{\text {eq }}\left(V_{T_{1}}, F_{1}, T^{*}(\beta)\right)$, the shareholder's preference is not really binding and the maximum reservation price possible is strictly larger than the reservation price. For reservation prices larger than $W_{\text {eq }}\left(V_{T_{1}}, F_{1}, T^{*}(\beta)\right)$ (and up to the maximum value compatible with the creditor's preferences $\left.W_{\text {eq }}\left(V_{T_{1}}, F_{1}, T_{\max }^{\text {de }}(\beta)\right)\right)$, the shareholder's preference $K$ is really binding and it is the maximum level possible. Reservation prices $K$ above $W_{\text {eq }}\left(V_{T_{1}}, F_{1}, T_{\max }^{\mathrm{de}}(\beta)\right)=K_{\max }^{\mathrm{de}}\left(T_{\max }^{\mathrm{de}}(\beta)\right)$ are just irreconcilable with the creditor's preference and the function $K^{*}(K)$ is simply not defined there. Anticipating next simulations, it is worth noticing that rescheduling in Figure 1 is possible or not depending on reservation prices. When the creditor's reservation price is low with $\beta^{\prime}=20 \%$, liquidation costs are high and the maximum extra period possible is rather long because $\tau_{\max }^{\mathrm{de}}\left(\beta^{\prime}\right)=18.55$. When the reservation price is higher with $\beta=40 \%$, liquidation costs are still significant but smaller in magnitude. The maximum extra period possible is then shorter and equal to $\tau_{\max }^{\mathrm{de}}(\beta)=10.33$. When the shareholder's reservation price is constant and equal to $K=7$, the minimum extra period is $\tau_{\min }^{\mathrm{eq}}(K)=7.72$. For 
$K^{\prime}=10.5$, it is $\tau_{\min }^{\text {eq }}\left(K^{\prime}\right)=11.40$. Consequently, when the shareholder's reservation price is $K=7$, a rescheduling is possible in both scenarios of liquidation costs. When it is equal to $K^{\prime}=10.5$, rescheduling is possible only for $\beta^{\prime}=20 \%$. In that case, the creditor's reservation price (function of the realization rate or equivalently liquidation costs) is not that constraining. In no case here, the optimal rescheduling advocated by Longstaff (1990) is feasible because both $\tau_{L}^{*}(\beta)$ and $\tau_{L}^{*}\left(\beta^{\prime}\right)$ indicate extra periods of time smaller than $\tau_{\min }^{\mathrm{eq}}(K)$ and $\tau_{\min }^{\mathrm{eq}}\left(K^{\prime}\right)$.

\section{INSERT FIGURE 1 SOMEWHERE HERE}

Figure 2 illustrates effects of reservation prices. In the upper left hand graph, we reconsider the creditor's net gain function drawn in Figure 1 (with associated key extra periods $\tau_{L}^{*}\left(\beta^{\prime}\right)$ and $\left.\tau_{\max }^{\text {de }}\left(\beta^{\prime}\right)\right)$ and we add two minimum extra periods required by the shareholder to cover reservation prices $\tau_{\min }^{\mathrm{eq}}\left(K^{\prime}\right)$ and $\tau_{\min }^{\mathrm{eq}}\left(K^{\prime \prime}\right)$. We consider a couple of reservation prices here to help discussion $\left(K^{\prime}=10.5\right.$ has been already considered in Figure 1 while $K^{\prime \prime}=1$ is newly introduced for expositional reasons). The graph also emphasizes the net gain function value $H_{\text {debt }}\left(\tau_{L}^{*}\left(\beta^{\prime}\right)\right)$ at the optimal rescheduling horizon $\tau_{L}^{*}\left(\beta^{\prime}\right)$, the cost of opportunity borne by the creditor if he chooses $\tau_{\min }^{\text {eq }}\left(K^{\prime}\right)$ for rescheduling and three different zones associated to $K^{\prime}$ and $\beta^{\prime}$. "R Zone" points to possible extra periods for rescheduling, "NR Zone 'C"' precises horizons above $\tau_{\max }^{\mathrm{de}}(\beta$ ') the creditor cannot choose and "NR Zone 'S"' indicates horizons below $\tau_{\text {min }}^{\text {eq }}\left(K^{\prime}\right)$ the shareholder can only reject ${ }^{18}$. Because $\tau_{\min }^{\text {eq }}\left(K^{\prime}\right)$ lies between $\tau_{L}^{*}\left(\beta^{\prime}\right)$ and $\tau_{\max }^{\text {de }}\left(\beta^{\prime}\right)$, Proposition 4 predicts that the best choice for the extra period is the minimum horizon required by the shareholder $\tau_{\min }^{\mathrm{eq}}\left(K^{\prime}\right)$. This is indeed the minimum opportunity cost the creditor can bear. By passing, extra periods associated to

\footnotetext{
${ }^{18}$ Note that, for some range of parameters, very short horizons may be impossible for both the creditor and the shareholder (see footnote 12).
} 
"small" reservation prices, like $K^{\prime \prime}=1$, appear smaller than $\tau_{L}^{*}\left(\beta^{\prime}\right)$, so that the creditor can choose in this context the optimal rescheduling design with the consent of the shareholder. The upper right graph Figure 2 displays the shareholder's benchmark function viewed as a function of extra periods of time $\tau=T-T_{1}$ (along with key horizons and zoning). This graph shows that the shareholder is systematically better off increasing rescheduling maturity and it indicates how good a longer rescheduling is for her.

The lower left graph completes the picture by providing the total value of the firm viewed as a function of extra periods of time $\tau=T-T_{1}$. Interestingly the firm's total value is increasing with respect to the extra period of time granted by the creditor. Hence, a social planner in charge of the rescheduling and acting for the best of the firm as a whole (and as such employing the total firm value as a criterion) may decide a restructuring hurting the creditor's interests and favoring the shareholder.

The lower right graph sheds more lights finally on the stakeholders' benchmark functions when $\tau_{\min }^{\mathrm{eq}}$ varies, i.e. when the shareholder's reservation price is changing accordingly. We clearly observe the creditor's opportunity cost increasing almost linearly when $\tau_{\min }^{\text {eq }}$ increases beyond $\tau_{L}^{*}\left(\beta^{\prime}\right)$. But, when the reservation price is moderate and $\tau_{\min }^{\mathrm{eq}}$ rather small (smaller that $\tau_{L}^{*}\left(\beta^{\prime}\right)$ actually), the creditor does not care about it. Optimal rescheduling is possible there and most importantly he can enjoy the maximum net gain. For larger reservation price, the creditor must accept to grant a non-optimal rescheduling made of (at best) the extra period $\tau_{\min }^{\text {eq }} 19$. The net gain function of the creditor decreases as the reservation price $K$ increases, until rescheduling is no more feasible. When the period $\tau_{\min }^{\mathrm{eq}}$ is longer, the shareholder's benchmark function decreases due to the increasing feature of the corresponding reservation price we can denote by $K\left(\tau_{\text {min }}^{\text {eq }}\right)$. Actually, this reflects the fact that when the period $\tau_{\min }^{\mathrm{eq}}$ is lower than $\tau_{L}^{*}\left(\beta^{\prime}\right)$, the rescheduling period is in all cases set to $\tau_{L}^{*}\left(\beta^{\prime}\right)$

\footnotetext{
${ }^{19}$ The bargaining power of each party may then be important to determine what final horizon emerges within the range $\left[T_{\min }^{\mathrm{eq}}, T_{\max }^{\mathrm{de}}\right]$ (see section 5.3).
} 
and the equity value does not change. Here only the reservation price varies within the benchmark function formula and the plot reveals that $K\left(\tau_{\min }^{\mathrm{eq}}\right)$ is a non linear function of $\tau_{\min }^{\mathrm{eq}}$.

\section{INSERT FIGURE 2 SOMEWHERE HERE}

Let us now gain in Table 1 some numerical intuitions about the shareholder's reservation price effect. We reconsider here quantitative scenarios studied by Longstaff (1990) in his Tables 1 and 2. For comparison purpose, parameter values are similar to those chosen by him, so that $V_{T_{1}}=34, F_{1}=40, \sigma=20 \%, r=6 \%$ and the magnitude of the realization rate $\beta$ is ranging from $65 \%$ to $95 \%$ in the first column of Table 1 . We also introduce the shareholder's reservation price and set it to $K=1$. Columns 2 to 8 display simulations on the optimal rescheduling period $\tau_{L}^{*}(\beta)$ solving the unconstrained optimization program (2), the longest rescheduling period possible for the creditor $\tau_{\max }^{\mathrm{de}}(\beta)$, the minimum rescheduling period required by the shareholder $\tau_{\min }^{\text {eq }}(K)$, the creditor's net gain function and the value of equity computed at the optimal rescheduling horizon advocated by Longstaff (1990) $\left(H_{\text {debt }}\left(\tau_{L}^{*}(\beta)\right)\right.$ and $\left.E q\left(\tau_{L}^{*}(\beta)\right)\right)$ in the next two columns, and then the same computed at the optimal rescheduling horizon according to the constrained optimization problem (4) $\left(H_{\text {debt }}\left(\tau^{*}\left(V_{T_{1}}, K, \beta\right)\right)\right.$ and $\left.E q\left(\tau^{*}\left(V_{T_{1}}, K, \beta\right)\right)\right)$. Finally the maximum shareholder's reservation price the environment can tolerate is given in column 8 . The last and ninth column concludes with respect to the rescheduling decision.

\section{INSERT TABLE 1 SOMEWHERE HERE}

Table 1 first emphasizes a grey zone to highlight situations where the creditor can effectively implement the Longstaff's optimal rescheduling design. A simple way to check this is to search situations for which $H_{\text {debt }}\left(\tau^{*}\left(V_{T_{1}}, K, \beta\right)\right)$ is equal to $H_{\text {debt }}\left(\tau_{L}^{*}(\beta)\right)$ or equivalently where the value of equity is larger than the considered reservation price $(K=1)$. We observe that 
Longstaff's solutions apply for realization rates up to and included $\beta=80 \%$. The minimum horizon $\tau_{\min }^{\text {eq }}(K)$ implied by the (small) shareholder's reservation price is indeed lower than the optimal period of time $\tau_{L}^{*}(\beta)$. The first best choice of the creditor $\left(\tau_{L}^{*}(\beta)\right)$ is then possible and reservation price $(K=1)$ is not here a constraint. When realization rate is higher than $85 \%$, things change dramatically. If $\beta$ is equal to $85 \%$, then rescheduling is still feasible because it is worth doing so for the creditor. One may check that $\tau_{\min }^{\mathrm{eq}}(K)<\tau_{\max }^{\mathrm{de}}(\beta)$ or equivalently that $H_{\text {debt }}\left(\tau^{*}\left(V_{T_{1}}, K, \beta\right)\right)$ is positive. But now, rescheduling is suboptimal for the creditor because $\tau_{L}^{*}(\beta)<\tau_{\min }^{\mathrm{eq}}(K)$ and the rescheduling duration can only be a second best. As suggested by Proposition 4, opportunity costs borne by the creditor can be assessed by subtracting $H_{\text {debt }}\left(\tau^{*}\left(V_{T_{1}}, K, \beta\right)\right)$ to $H_{\text {debt }}\left(\tau_{L}^{*}(\beta)\right)$. Opportunity costs he faces here amount to $H_{\text {debt }}\left(\tau_{L}^{*}(\beta)\right)-H_{\text {debt }}\left(\tau^{*}\left(V_{T_{1}}, K, \beta\right)\right)=0.51-0.47=0.04$, which is about $8 \%$. As expected from Figure 2 (see the lower right graph), the shareholder receives a claim here that is exactly worth 1 and covers her reservation price. It bounds the value of the claim she receives in case of rescheduling. By comparison to the canonical situation, her wealth has increased by about half $\left(\frac{1}{0.65}=1.54\right)$. Interestingly, the absolute value of such an increase is higher than the opportunity cost borne by the creditor, stressing that this constrained rescheduling is socially beneficial. The magnitude of $K_{\max }$ confirms finally that such an environment could have supported higher reservation price (up to 2.11). For betas equal to or greater than $90 \%$, $\tau_{\max }^{\mathrm{de}}(\beta)$ is now lower than $\tau_{\min }^{\mathrm{eq}}(K)$ meaning that tolerances are irreconcilable and no rescheduling can occur without implementing an exit strategy (see section 5 for more information). There is just no more solution to the constrained optimization program (4) and hence no rescheduling possibility. Maybe this is not a so bad news because we simply avoid situations where (in view of columns $H_{\text {debt }}\left(\tau_{L}^{*}(\beta)\right)$ and $E q\left(\tau_{L}^{*}(\beta)\right)$ ) rescheduling is not that critical and the stake certainly negligible. The column dedicated to $K_{\max }$ gives another way to understand the situation by showing how the maximum reservation price shareholders can accept is lower than the one we consider. 


\section{Further issues on corporate debt rescheduling with reservation prices}

What about agency costs in corporate debt rescheduling with reservation prices? How to avoid the failure of rescheduling negotiation? What about the influence of bargaining power in the rescheduling design? Next paragraphs elaborate on these questions within the extended structural framework.

\subsection{Ex post renegotiation moves and agency costs}

Recent evidences show that corporate policies significantly change following financial arrangement (Eisdorfer (2008), Esmer (2013)). Esmer (2013) finds for instance that risk-shifting occurs even in the presence of increased creditor's control. One may expect this propensity to be exacerbated in stressed situations such as rescheduling negotiation ${ }^{20}$. In our setting; the firm's assets' volatility is the natural (and actually only) candidate to capture this issue. We expect from the traditional corporate finance literature agency concerns.

To assess the extent to which the shareholder has incentives to change the volatility ex post renegotiation, we can simply compute $E q(\sigma(1+\Delta \sigma \%), T(\sigma))-E q(\sigma, T(\sigma))$ and $\frac{E q(\sigma(1+\% \sigma), T(\sigma))-E q(\sigma, T(\sigma))}{E q(\sigma, T(\sigma))}$ these are the absolute and relative price differences of equity price when the firm's assets volatility is changed (by a percentage $\Delta \sigma \%$ ) everywhere except in the determination of the rescheduling maturity. The absolute price difference is measured in euros or dollars, the relative one in percentage of the negotiated claim's price. Corresponding agency costs may be computed by applying the same formulae to the debt price. We denote by $\Delta$ Claim $(T)$ and $\Delta^{\%} \operatorname{Claim}(T)$ the above measures, where Claim can stand for either debt or equity.

\footnotetext{
${ }^{20}$ Two kinds of strategies can occur after the rescheduling decision. The first one modifies parameters involved in the (risk neutral) decision process. The second one modifies parameters that do not directly impact the pricing problem at renegotiation. Here we can think about the expected (objective) rate of return of the firm's assets as a driver for such strategies... The real expected rate of return is currently hidden in the decision rescheduling process but it has potentiality to conciliate both parties. They should probably account for this earlier in the process i.e. during renegotiation. So we explore this point in a following paragraph.
} 
Figure 3 plots two different graphs one for each measure. Both represent variations of debt and equity price on the same draw in order to compare magnitudes. We also consider a couple of rescheduling designs that are an optimal one designed by $\tau_{L}^{*}(\beta)$ and an other one constrained by the shareholder's reservation price and the rescheduling horizon $\tau_{\min }^{\text {eq }}\left(K^{\prime}\right)$. Structural parameters are similar to those of previous Figures.

\section{INSERT FIGURE 3 SOMEWHERE HERE}

Let's have a look first at volatility increasing from $\sigma$ to $\sigma_{n}=\sigma\left(1+\Delta^{\%} \sigma\right)$ for positive $\Delta^{\%} \sigma$. As expected, both $\Delta E q(T)$ and $\Delta^{\%} E q(T)$ are strictly positive meaning that there is an incentive for the shareholder to increase the volatility ex post rescheduling. The right graph indicates that $\Delta^{\%} E q$ almost doubles when $\Delta^{\%} \sigma$ is positive $\left(\Delta^{\%} E q\left(\tau_{L}^{*}\left(\beta^{\prime}\right)\right) \approx 2 \times \Delta^{\%} E q\left(\tau_{\min }^{\mathrm{eq}}\left(K^{\prime}\right)\right)\right.$, meaning that the shareholder is significantly better off in relative terms by modifying the volatility of the optimal rescheduling. Another result is that the situation is not symmetric in the sense that the creditor does not face the loss that could correspond to the gain the shareholder enjoys (in both absolute and relative terms). The volatility effect is indeed not ranked the same, one has $\left|\Delta^{\%} D\left(\tau_{L}^{*}\left(\beta^{\prime}\right)\right)\right|<\left|\Delta^{\%} D\left(\tau_{\min }^{\mathrm{eq}}\left(K^{\prime}\right)\right)\right|$ and $\left|\Delta^{\%} E\left(\tau_{\min }^{\mathrm{eq}}\left(K^{\prime}\right)\right)\right|<\left|\Delta^{\%} E\left(\tau_{L}^{*}\left(\beta^{\prime}\right)\right)\right|$ when $\Delta^{\%} \sigma$ is positive. Explanation for this comes from the total firm's value, which does not stay the same when the volatility is modified. We can deduce from this that the shareholder can capture most of the created value. Let's now have a look at volatility lowering from $\sigma$ to $\sigma_{n}=\sigma\left(1+\Delta^{\%} \sigma\right)$ for negative $\Delta^{\%} \sigma$. As expected from corporate literature, there is no such incentive for the shareholder. Less intuitively, the effect is differently appreciated by the creditor. In line with standard theory, the creditor can be better off by lowering volatility, but this is not always the case if he designed rescheduling optimally. In such a case, the creditor can benefit from a small to moderate volatility change but he can then suffer from larger moves. The key driver of this is liquidation costs and the fact that the rescheduling horizon is fixed (and short). Lowering the volatility may decrease the (risk neutral) probability of recovery and increase the probability to face liquidation costs later. 


\subsection{How to make rescheduling feasible?}

In real life, rescheduling may actually fail for different reasons but the setting we consider suggest to have a look at some key determinants. First of all, the reservation price the shareholder has in mind may be too large or too steep (in case of a linear specification). To decrease the value or the slope of the reservation price, one may search for a "white knight" with lower requirements but still able to restore the firm ${ }^{21}$. This may force stakeholders to search actively for a key talent. Stakeholders can also change the firm's business characteristics and modify either its risk profile (that is the volatility) or the intangible nature of assets (that is the realization rate) or both. These possible solutions affect stakeholders differently and we explore this now.

Reservation price has clearly an impact on the shareholder's tolerance for rescheduling (see the lower right graph of Figure 2 for early results on this). This is not however a possible lever for altering the creditor's tolerance because the reservation price simply does not enter the (unconstrained) objective function of the creditor. So neither $\tau_{L}^{*}(\beta)$ nor $T_{\max }^{\text {de }}(\beta)$ depends on $K$. The benefit of lowering reservation price can be assessed by measuring how the horizon $T_{\min }^{\mathrm{eq}}(K)$ is changing when $K$ is modified. This function of $K$ is defined (implicitly) by $H_{\text {debt }}\left(V_{T_{1}}, F_{1}, T_{\text {min }}^{\text {eq }}(K) ; K\right)=0$. Within the extended canonical setting, simple calculus leads to

$$
\frac{\partial T_{\min }^{\mathrm{eq}}(K)}{\partial K}=\frac{1}{\frac{V_{T_{1}} \sigma}{2 \sqrt{T_{\text {min }}^{\mathrm{eq}}-T_{1}}} n\left(d_{1, V_{T_{1}} / F_{1}}\left(T_{\min }^{\mathrm{eq}}-T_{1}\right)\right)+r F_{1} e^{-r\left(T_{\min }^{\mathrm{eq}}-T_{1}\right)} N\left[d_{2, V_{T_{1}} / F_{1}}\left(T_{\min }^{\mathrm{eq}}-T_{1}\right)\right]}
$$

where $n$ stands for the normal cumulative distribution function. The value of this is of course positive but its magnitude can significantly change depending on parameters.

Changing the firm's business profile can significantly influence the design of rescheduling and the tolerance of shareholders. Parties may question industrial restructuring strategies that may be worth for both. Both the assets' volatility $\sigma$ and the realization rate $\beta$

${ }^{21}$ Takacs (2011) shows for instance that in LBOs restructuring managers are fired in approximately $40 \%$ of cases. 
capture the business profile of the firm in our setting; $\sigma$ stands for the business risk while $\beta$ reveals the nature of assets in terms of tangibility, obsolescence, specificity, demand, etc. Analysis reveals that changing $\beta$ is essentially of little help in our setting. First of all, this is not a lever for changing the shareholder's tolerance because the horizon $T_{\min }^{\mathrm{eq}}(K)$ does not depend on $K$. For the creditor's tolerance, calculus yieds to

$$
\frac{\partial T_{\max }^{\mathrm{de}}(\beta)}{\partial \beta}=\frac{V_{T_{1}} N\left[-d_{1, V_{T_{1}} / F_{1}}\left(T_{\max }^{\mathrm{de}}-T_{1}\right)\right]}{-\frac{V_{T_{1}} \sigma}{2 \sqrt{T_{\text {max }}^{\mathrm{de}}-T_{1}}} n\left(d_{1, V_{T_{1}} / F_{1}}\left(T_{\max }^{\mathrm{de}}-T_{1}\right)\right)-r F_{1} e^{-r\left(T_{\max }^{\mathrm{de}}-T_{1}\right)} N\left[d_{2, V_{T_{1}} / F_{1}}\left(T_{\max }^{\mathrm{de}}-T_{1}\right)\right]+V_{T_{1}} N\left[-d_{1, V_{T_{1}} / F_{1}}\left(T_{\text {max }}^{\mathrm{de}}-T_{1}\right)\right]}
$$

And it is not that clear whether this derivative is systematically negative for all ranges of structural parameters even if for most of them it is (see the left graph of Figure 1 for a typical example). So decreasing the realization rate increases the set of possible rescheduling horizons but the critical point here is that it also decreases the value the creditor can get in case of future default. This is not good news for the creditor so that he will certainly refuse. To see this analytically, one can verify that the first derivative of the debt value with respect to $\beta\left(\frac{\partial D_{\text {debt }}\left(V_{T_{1}}, F_{1}, T ; \beta\right)}{\partial \beta}=\int e^{-r\left(T_{2}-T_{1}\right)} V_{T_{2}} 1_{V_{T_{2}}<F_{1}} f\left(V_{T_{2}} \mid V_{T_{1}}\right) d V_{T_{2}}\right)$ is always positive.

So, only a change in the firm's risk profile could make rescheduling feasible and we expect both rescheduling design and tolerances to be impacted. Calculus in the structural setting leads to $\frac{\partial T_{\min }^{\mathrm{eq}}(\sigma)}{\partial \sigma}=-\frac{V_{T_{1}} \sqrt{T_{\min }^{\mathrm{eq}}-T_{1}} n\left(d_{1, V_{T_{1}} / F_{1}}\left(T_{\min }^{\mathrm{eq}}-T_{1}\right)\right)}{\frac{V_{T_{1}} \sigma}{2 \sqrt{T_{\text {min }}^{\mathrm{eq}}-T_{1}}} n\left(d_{1, V_{T_{1}} / F_{1}}\left(T_{\min }^{\mathrm{eq}}-T_{1}\right)\right)+r F_{1} e^{-r\left(T_{\min }^{\mathrm{eq}}-T_{1}\right)} N\left[d_{2, V_{T_{1}} / F_{1}}\left(T_{\min }^{\mathrm{eq}}-T_{1}\right)\right]}$ which is always negative so that (as expected) $T_{\min }^{\mathrm{eq}}(\sigma)$ decreases when the firm's assets volatility increases. By changing the firm's asset volatility, one can change the tolerance of the representative shareholder. Analytical calculus for $\frac{\partial T_{\max }^{\mathrm{debt}}(\sigma)}{\partial \sigma}$ and $\frac{\partial T_{L}^{*}(\sigma)}{\partial \sigma}$ are possible too but their intricate expression does not unfortunately provide any clear expression especially to compare with $\frac{\partial T_{\min }^{\mathrm{eq}}(\sigma)}{\partial \sigma}$. So we use simulations and refer to Figure 4. 
Figure 4 plots four graphs. The upper left graph illustrates, for a couple of business risk profiles, how lowering the shareholders' reservation price decreases the minimum horizon required by the shareholder, viewed as a tolerance to rescheduling. The riskier the firm's business, the more likely a (granted) extra period covers the shareholder's reservation price; but the larger the effort (in terms of $K$ ) to lower the minimum horizon by a similar amount. Stakeholders may also think about increasing the business risk of the firm so as to relax in some ways the constraint induced by reservation prices. The upper right graph shows however this latter solution is not necessarily that straightforward to implement in our specific context. First of all, both $T_{\min }^{\mathrm{eq}}(\sigma)$ and $T_{\max }^{\mathrm{de}}(\sigma)$ are indeed decreasing when the level of business risk is increasing. And second both interact to define the rescheduling. Hence, the challenge for stakeholders is to appreciate the relative speed of change of both horizons with respect to volatility. The upper right graph also sheds lights on this issue. We put together horizons associated to the creditor (solid lines) and the shareholder (dashed and dotted lines) given that she has a reservation price of 7 or 2.5. $T_{L}^{*}, T_{\min }^{\mathrm{eq}}(K=2.5), T_{\min }^{\mathrm{eq}}(K=7)$ and $T_{\max }^{\mathrm{de}}$ are all functions of $\sigma$. Inspection of $T_{\min }^{\mathrm{eq}}(K=2.5)$ and $T_{\min }^{\mathrm{eq}}(K=7)$ reveals that curves cross those of $T_{\max }^{\text {de }}$ and $T_{L}^{*}$ proving that rescheduling may or may not be possible and that creditors can expect or not the maximum net gain function depending on the volatility they choose. Comments are in lines with properties highlighted in Table $1^{22}$. The lower right graph sums up possible designs for rescheduling with a straight line when an optimal design is possible and doted or dashed lines for sub-optimal designs. The lower left graph plots corresponding

${ }^{22}$ Let us first consider for instance $K=2.5$, it appears that rescheduling is always possible because $T_{\max }^{\text {de }}$ is above $T_{\min }^{\mathrm{eq}}(K=2.5)$ for all studied values of $\sigma$. But, depending on the level of business risk, the maximum net gain function for the creditor is not necessarily achievable when deciding rescheduling. For $\sigma$ approximately lower than or equal to $20 \%$, the minimum horizon required by shareholders $T_{\min }^{\mathrm{eq}}(K=2.5)$ is smaller than $T_{L}^{*}$ the best horizon the creditor can choose: so that he can implement his optimal design. For higher values of $\sigma$, he will choose $T_{\min }^{\mathrm{eq}}(K=2.5)$ - the horizon required by the shareholder to cover reservation price. We know this horizon minimizes creditor's opportunity costs, but also that the shareholder receives $K=2.5$ only (so whatever the volatility is). For higher values of reservation price, the rescheduling may be impossible. The curve associated to $T_{\min }^{\mathrm{eq}}(K=7)$ is indeed higher than $T_{\max }^{\mathrm{de}}$ for $\sigma$ approximately higher than $30 \%$. In these business risk environments, tolerances are incompatible and irreconcilable. 
prices of corporate debt. When design is always sub-optimal (like for $K=7$ ), we know that creditor chooses $T_{\min }^{\mathrm{eq}}(\sigma)$ for rescheduling horizon and that the new equity is worth exactly $K$. Consequently, the shareholder will be indifferent to a change in volatility because the new possible volatility can only maintain $T_{\max }^{\mathrm{de}}(\sigma)<T_{\min }^{\mathrm{eq}}(\sigma)$. When the design is optimal (like for $K=2.5$ for small values of volatility), we stand in the canonical framework of Longstaff (1990) and we know thanks to Moraux and Navatte (2007) that there exists a suitable business risk level to target before entering renegotiation.

\section{INSERT FIGURE 4 SOMEWHERE HERE}

\subsection{Introducing relative bargaining power}

The previous framework investigates situations where the creditor decides the rescheduling period at the best of his interest under the constraint that the considered rescheduling horizon remains acceptable by the representative shareholder. In many concrete situations, however, the representative shareholder can influence the rescheduling design i.e. can co-decide the length of the rescheduling period. Such a representative shareholder's bargaining power goes beyond the simple veto previously considered.

Mathematically, the net gain function of the representative shareholder enters the objective function and we face an asymmetric generalized Nash bargaining problem. The objective function to maximize is now made of both net gain function and it may be written : $H_{\text {Nash }}^{\eta}\left(V_{T_{1}}, F_{1}, T_{1}+\tau ; \beta, K(\tau), \eta\right)=H_{\text {debt }}\left(V_{T_{1}}, F_{1}, T_{1}+\tau ; \beta\right)^{1-\eta} H_{\text {eq }}\left(V_{T_{1}}, F_{1}, T_{1}+\tau ; K(\tau)\right)^{\eta}$, where the parameter $\eta$ (such that $0<\eta<1$ ) stands for the shareholder's influence on the rescheduling duration (through the objective function) and where, symmetrically, $1-\eta$ represents the creditor's influence on the rescheduling duration through the objective function. This objective function maintains the net gain function of the creditor and the benchmark function of the shareholder both positive. In case $\eta=0$, the objective function to maximize is $H_{\mathrm{de}}$ that is the net gain function of the creditor and the shareholder has only a direct influence on the length of the rescheduling period through her veto. In case $\eta=1$ (i.e. 
$1-\eta=0)$, the objective function to maximize is $H_{\mathrm{eq}}$ that is the benchmark function of the representative shareholder but the creditor enjoys a direct influence on the length of the rescheduling period through his veto. The above objective function is properly defined on a compact set of horizon only which is defined by $\left[T_{\min }^{\mathrm{eq}}(k) ; \min \left(T_{\max }^{\mathrm{de}}(\beta), T_{\max }^{\mathrm{eq}}(k)\right)\right]$ in case linear reservation prices are considered and $\left[T_{\min }^{\mathrm{eq}} ; T_{\max }^{\mathrm{de}}(\beta)\right]$ for the constant case. Bounds of this set just pick the most constraining horizons. In any case, the optimal rescheduling period (if any) is

$\tau^{*}\left(V_{T_{1}}, \beta, K(\tau), \eta\right)=\arg \max _{\tau>0} H_{\text {Nash }}^{\eta}\left(V_{T_{1}}, F_{1}, T_{1}+\tau ; \beta, K(\tau), \eta\right)$.

\section{INSERT FIGURE 5 SOMEWHERE HERE}

Figure 5 plots $H_{\text {Nash }}^{\eta}$ the objective function associated to the asymmetric Nash bargaining game from the viewpoints of stakeholders. Graphs on the left are associated to the creditor while those on the right correspond to the representative shareholder. In upper graphs (Panel A), we set the reward for effort per unit of time to a moderate value of $k=0.5$ so as to maintain $\tau_{\text {min }}^{\text {eq }}(k)$ lower than $\tau_{L}^{*}\left(\beta^{\prime}\right)$. In lower graphs (Panel B), we set the reward for effort per unit of time to a larger value so as to make $\tau_{\min }^{\text {eq }}(k)$ greater than $\tau_{L}^{*}\left(\beta^{\prime}\right)$. In absence of any Nash bargaining game, the creditor can implement his first best choice in Panel A, while he cannot in Panel B, where he can only consider his second best horizon. Considering now $H_{\text {Nash }}^{\eta}$ the objective function associated to the asymmetric Nash bargaining game, we observe that it is defined on a restricted set of horizons $\left[T_{\min }^{\mathrm{eq}}(k) ; \min \left(T_{\max }^{\mathrm{de}}(\beta), T_{\max }^{\mathrm{eq}}(k)\right)\right]$ that its maximum points in all cases to durations significantly different from the first and second best ones. Hence, the bargaining game for the design of the rescheduling can dramatically influence the duration chosen by stakeholders... and even more significantly than the (simple) veto considered before. The marginal opportunity cost faced by the creditor due to the bargaining game $\left(\operatorname{Debt}\left(V_{T_{1}}, F_{1}, \tau_{\text {Nash }}^{*}(\eta)\right)-\operatorname{Debt}\left(V_{T_{1}}, F_{1}, \max \left(\tau_{L}^{*}(\beta), \tau_{\min }^{\mathrm{eq}}(K)\right)\right)\right)$ appears higher 
than the one he faced by the existence of the veto $\left(\operatorname{Debt}\left(V_{T_{1}}, F_{1}, \tau_{L}^{*}(\beta)\right)-\operatorname{Debt}\left(V_{T_{1}}, F_{1}, \tau_{\min }^{\mathrm{eq}}(K)\right)\right.$ according to proposition 4).

\section{Empirical implications}

The model has in turn a list of testable implications. First ones concern potential determinants of an agreed rescheduling. Arrival of a rescuer or any change in the managing team may lower the reservation price $K$ and may have a positive effect on the rescheduling negotiation. Simulations also stress that, for two firms facing similar reservation price, the probability of successful rescheduling should decrease with the level of the business risk. Terms of rescheduling can be useful to understand for external investors. First of all, they reveal information about the outcome creditor and shareholder expect. Second, terms of the agreement (once again) and the possible satisfaction of a shareholder's reservation price can constitute strong evidences of perceived quality by insiders. A satisfying rescheduling agreement may help discriminate among distressed firms. Another important question to investigate empirically is whether a rescheduling decision has some predictive power on potential recovery of the firm

Theory exposed in section 3 suggests different ways to make rescheduling possible. It could be interesting to study the strategic behavior of firm's management before and after entering the (official) distress and rescheduling periods. Section 5 reveals that changing the business risk of the firm (that could be approximated by the standard deviation of firm's EBIT) or / and the realization rate $\beta$ (specificity of assets, proportion of intangible assets) is a challenging but possible approach to find an agreement acceptable for shareholders. Why and in which situations alternative forms of agreement still subsist? Agency theory predicts that rescheduling can align interest of stakeholders better than debt write-off (see Harding and Sirmans (2002)). Finally, determinants of unsuccessful deals could also be worth investigating. As suggested here, both difficulties to restructure the existing firm's assets and inefficiencies of the market for corporate control could matter. 


\section{Concluding remarks}

When a representative shareholder has a (constant or linear) reservation price, known results on rescheduling of distressed debt may change dramatically. This is a goal of this paper to investigate the extent to which both reservation prices restrict the set of possible horizons the creditor can choose to design the rescheduled debt. We derive, in a general distribution-free setting, various analytical results and highlight situations where rescheduling is worth for both parties and situations where the creditor can even achieve the best design possible (i.e. the optimal design obtained with no constraint). We characterize cases where rescheduling is simply unfeasible. Essentially, a rescheduling may be viewed as a meeting of tolerances. For running numerical simulations, we extend the canonical model of Longstaff (1990) and give quantitative conditions under which such rescheduling will not be accepted by a representative shareholder due to her reservation price. We consider various reservation prices, all other structural parameters being constant, and verify that relaxing constraints increases the solution set or other way saying the lower the reservation price of the creditor (respectively of the shareholder), the larger the set of maturities he (respectively she) can consider.

This paper has in turn various managerial implications. When reservation price are not important, the question is whether the optimal rescheduling design can be achieved. When reservation price are significant, the question is whether a suboptimal rescheduling can take place. Both issues depend on the current business profile of the firm and the level of reservation price. These concerns leave a room for strategic decisions. Modifying the business profile is an issue of operational or industrial restructuring. This may be more or less feasible and costly, depending on the industry. Reducing reservation price may be an issue of changing current managers and representative shareholders. This could explain why shareholders occasionally fire managers when distress occurs (despite their knowledge, skills, experience, entrenchment in the firm) and why they sometimes just give up the firm and let new investors to come in.

Here the rationale is to make rescheduling possible by lowering reservation price. If ever neither corporate rescuer nor raider can intervene, shareholders may benefit from this 
situation. Actually, they can compel the debt holder to negotiate more than expected. Such a situation can explain bargaining power of poor performing manager and shareholders. Finally, our analysis suggests that the cutoff realization rate for refusing rescheduling is not one hundred percent as predicted by Longstaff (1990) but a lower value that depends on the shareholder's profile. Our microeconomic approach can then be enriched from the banker's perspective to account for portfolio risk concentration, competition, macroeconomic environment, regulation and other related issues. But such a richer agenda is left for future research. 


\section{References}

Andrade G, Kaplan S. 1998 How costly is financial (not economic) distress? Evidence from highly leveraged transactions that become distressed. Journal of Finance 53: 1443-1493.

Asquith P, Gertner R, Scharfstein D. 1994 Anatomy of financial distress: An examination of junk-bond issuers. Quarterly Journal of Economics 109: 625-658.

Black F, Scholes M. 1973 The pricing of options and corporate liabilities. Journal of Political Economy 81: 637-654.

Bris A, Welch I, Zhu N. 2006 The costs of bankruptcy: Chapter 7 liquidation versus chapter 11 reorganization. Journal of finance 61: 1253-1303.

Chen S.N., Lee S.Y., Tsai H.H. and W.H. Wu 2008 Extend the debt as it is not deeply out-ofthe-money", Economics Bulletin, 7(16), 1-6.

Davis A., Katok E., Kwasnica A. 2011 Do auctioneers pick optimal reserve prices? Management Science, 57(1):177-192.

Décamps J.P., Faure-Grimaud A. 1998 Pricing the gamble for resurrection and the consequences of renegotiation and debt design. Working paper.

Décamps J.P., Faure-Grimaud A. 2000 Bankruptcy costs, ex post renegotiation and gambling for resurrection. Finance, 21, 71-84.

Eisdorfer A. 2008 Empirical evidence of risk shifting in financially distressed firms. Journal of Finance 63: 609-637.

Esmer B. 2013. Creditor control rights and managerial risk shifting. working paper.

Fan J., Titman S., Twite 2012 An international comparison of capital structure and debt maturity choices. Journal of Financial and Quantitative Analysis, 47(1), 23-56.

Franks J., Sussman O. 2005 Financial distress and bank restructuring of small to medium size UK companies. Review of Finance, 9(1) 65-96.

Gilson S., John K., Lang L. 1990. Troubled debt restructurings: An empirical study of private reorganization of firms in default. Journal of Financial Economics 27. 315-353.

Harding J, Sirmans C. 2002 Renegotiation of troubled debt: The choice between discounted payoff and maturity extension. Real Estate Economics, 30: 475-503. 
Jensen M. C., Meckling W.H. 1976 Theory of The Firm : Managerial Behavior, Agency Costs and Ownership Structure, Journal of Financial Economics, 3, 305-360.

Lee S.Y., Chung Y.F., 2009 Extending the maturity of a defaulting debt - The Longstaff model revisited, Review of Pacific Basin Financial Markets and Policies. 12(1), 125-140 Longstaff F. 1990 Pricing options with extendible maturities: Analysis and applications. Journal of Finance. 45: 935-957.

Merton R. 1973 Theory of Rational Option Pricing. Bell Journal of Economics and Management Science 4(1): 141-183.

Merton R. 1974 On the pricing of corporate debt: The risk structure of interest rates. Journal of Finance. 29: 449-470.

Micucci G., Rossi P. 2010 Debt restructuring and the role of lending technologies. Working paper, Banca d'Italia, 45p.

Modigliani F.; Miller, M. 1958 The Cost of Capital, Corporation Finance and the Theory of Investment. American Economic Review 48 (3): 261-297.

Moraux F., Navatte P. 2007 Business risk targeting and rescheduling of distressed debt. Finance 28(2): 43-78.

Takacs A 2011: European Restructuring Report (Default, restructuring and recoveries in 2008-2010), working paper, Debtwire Europe. 


\section{Figure 1 : The creditor's net gain function, the shareholder's benchmark function, reservation prices and key horizons}
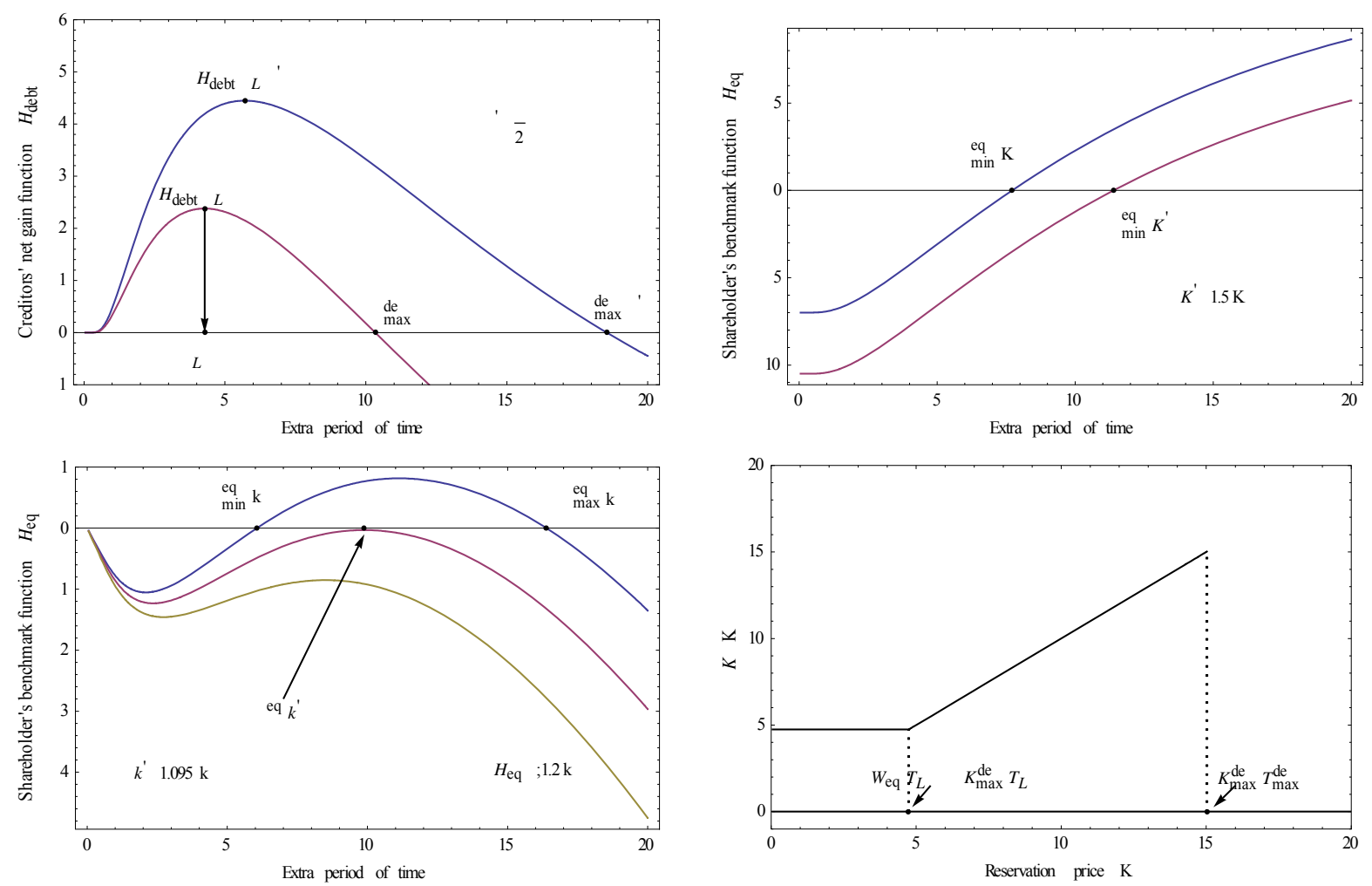

Figure 1 plots the net gain function of the creditor in left upper graph, the benchmark function of the representative shareholder whose reservation price is constant (right upper graph) or proportional to the duration (left lower graph) as functions of the extra period of time $\tau=T-T_{1}$ (that can be chosen for rescheduling) for different levels of reservation prices. The lower right graph represents the function $K^{*}(K)$ as a function of the reservation price. The left upper graph considers a couple of liquidation costs with fairly large values ( $\beta^{\prime}=40 \%$ and $\beta^{\prime}=20 \%$ ) for illustrative purposes. It highlights for both cases i) the maximum net gain the creditor can get $\left(H_{\text {debt }}\left(\tau_{L}^{*}\right)\right)$ if he chooses the optimal rescheduling delay $\tau_{L}^{*}$ and ii) the maximum rescheduling time-to-maturity he is ready to grant $\left(\tau_{\max }^{\mathrm{de}}\right)$. The right upper hand graph displays the shareholder's benchmark function $H_{\text {eq }}$ as a function of the extra period $\tau=T-T_{1}$ for a couple of reservation price $K=7$ and $K^{\prime}=10.5$. We highlight there minimum rescheduling durations $\tau_{\min }^{\text {eq }}(K)$ and $\tau_{\min }^{\text {eq }}\left(K^{\prime}\right)$ required to cover reservation prices. The lower left graph plots different possible scenarios arising when the reservation price is a linear function of the rescheduling duration. The base case sets the key parameter $k$ to 0.85 and the other ones are chosen so as to figure out two interesting alternative situations (with respectively one and zero roots). Other parameters are $V_{T_{1}}=20, F_{1}=40, \sigma=30 \%, r=10 \%$. 
Figure 2 : Reservation prices, values and opportunity costs
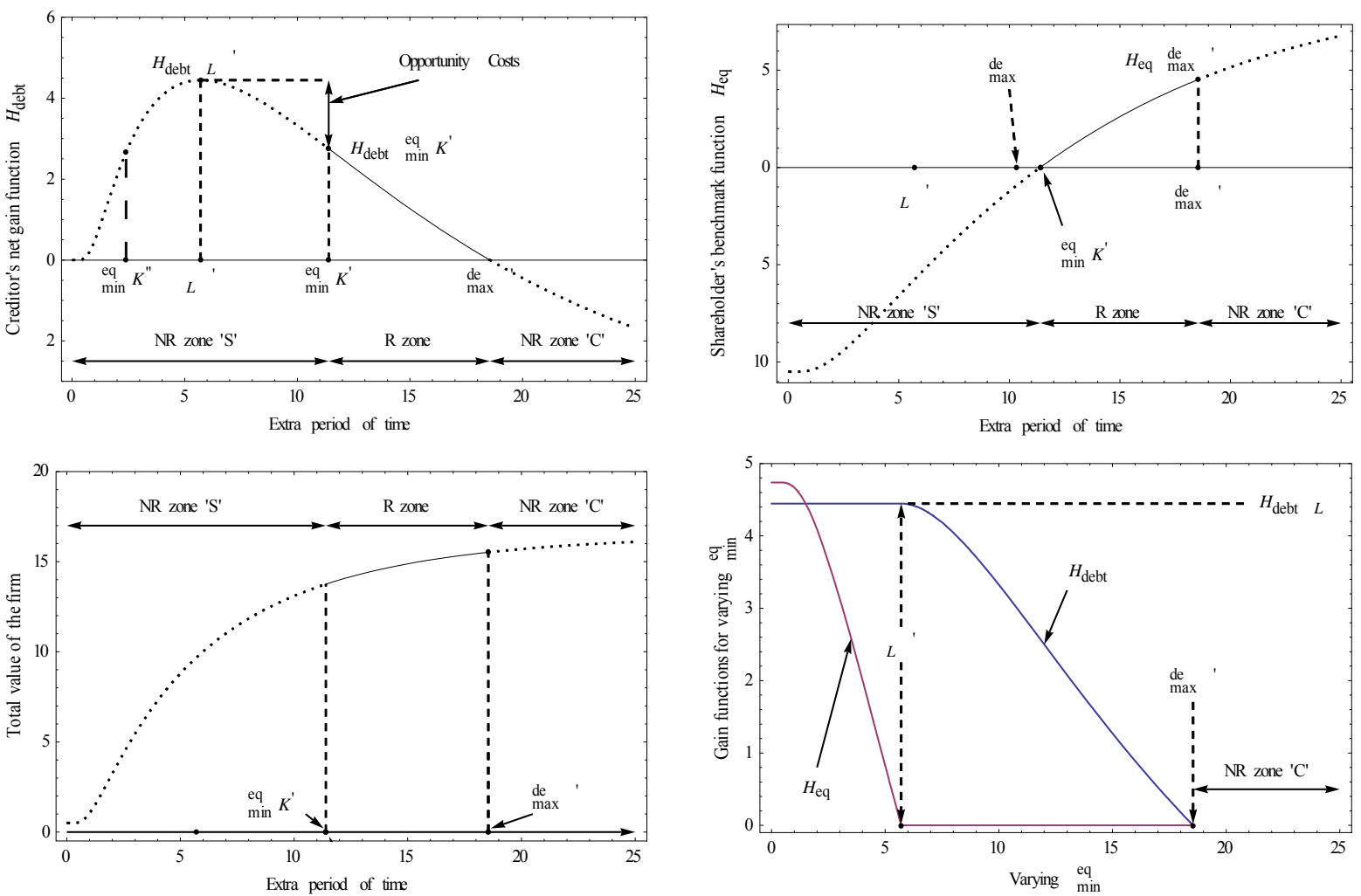

The upper left graph plots the creditor's net gain function $\left(H_{\text {debt }}\right)$ as a function of extra periods $\tau$."R Zone" points to extra periods admissible for rescheduling, The upper right graph plots the shareholder's benchmark function $\left(H_{\mathrm{eq}}\right)$ as a function of extra periods $\tau$. The lower left graph plots the total value of the firm. The lower right graph plots the creditor's net gain as a function of the minimum horizon required by the shareholder to cover her reservation price. "NR Zone 'C"' precises horizons the creditor cannot choose (so 'C') and "NR Zone ' $\mathrm{S}$ "' indicate horizons the shareholder can only reject (so ' $\mathrm{S}$ ') $\tau_{\max }^{\mathrm{de}}$ stands for the maximal period the creditor can accept, $\tau_{L}^{*}$ for the optimal rescheduling period he should rationally choose in absence of reservation price. Parameters are those of Figure 1. See the core text for additional details. 
Figure 3 : Activism after rescheduling the corporate distressed debt: from agency costs to a agreed common strategy
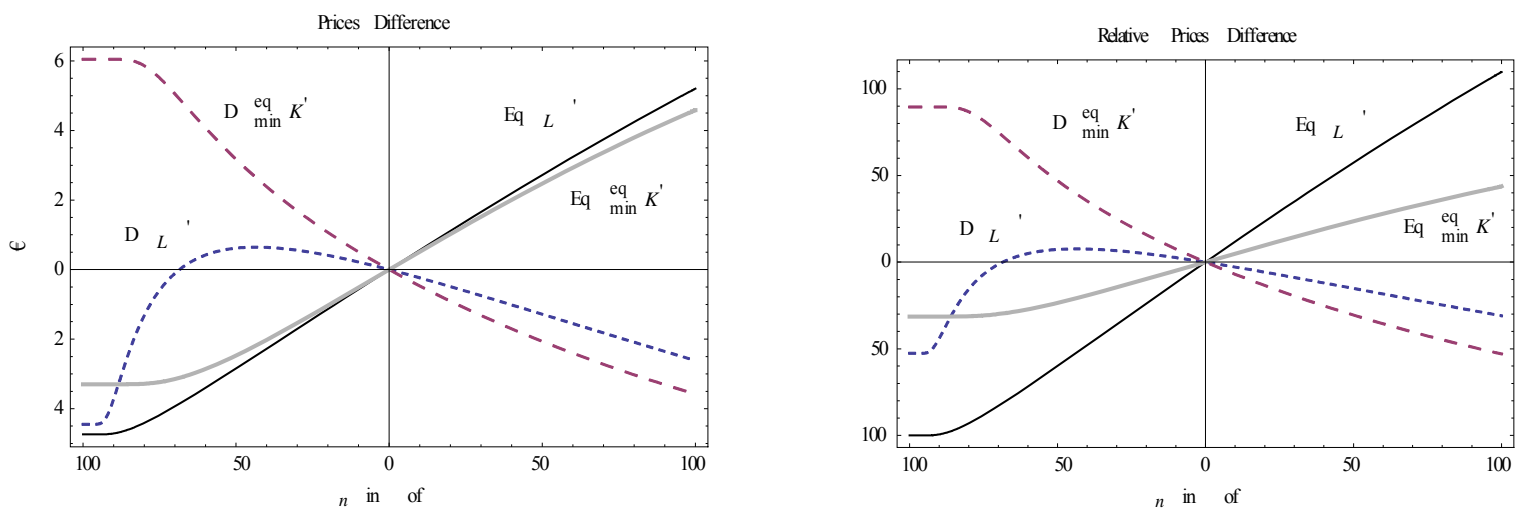

The left graph plots absolute price differences (in euros) as functions of the new volatility $\sigma_{n}=\sigma\left(1+\Delta^{\%} \sigma\right)$. The right graph plots relative price differences (in percentage) as functions of the new volatility $\sigma_{n}=\sigma\left(1+\Delta^{\%} \sigma\right)$. We consider both the debt price and the equity price and a couple of reschedulings. The new volatility is expressed in percentage of the initial volatility: the abscissa is therefore $\Delta^{\%} \sigma$. Parameters are those of Figure 1. 
Figure 4 : Stakeholders' tolerance to rescheduling and the price of the corporate debt
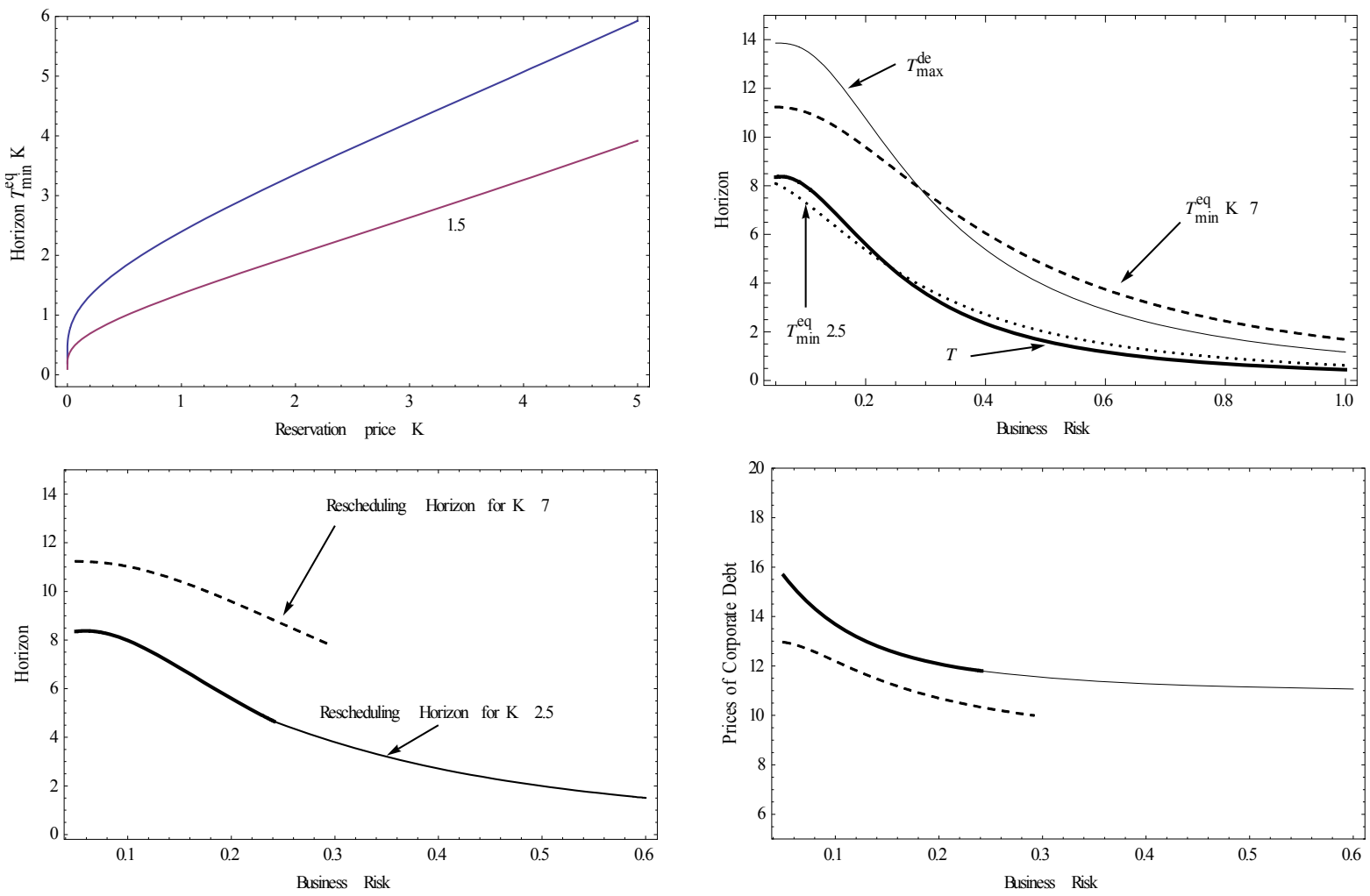

The left upper graph plots the minimum rescheduling duration $\tau_{\min }^{\mathrm{eq}}(K)$ as a function of the constant reservation for two different scenarios of business risk. The right upper graph represents various key durations used in our analysis. The left lower graph emphasizes the identity of the duration $\tau^{*}\left(V_{T_{1}}, K, \beta\right)$ that solves the constrained optimization problem of equation (4). The right lower graph plots the value of the corresponding corporate debt. Parameters are $V=34, F_{1}=40, \sigma=20 \%, r=6 \%$ and the realization rate is set to 50 percent. 
Figure 5 : The asymmetric Nash Bargaining game and the wealth of stakeholders

Panel A : $k=0.5$.
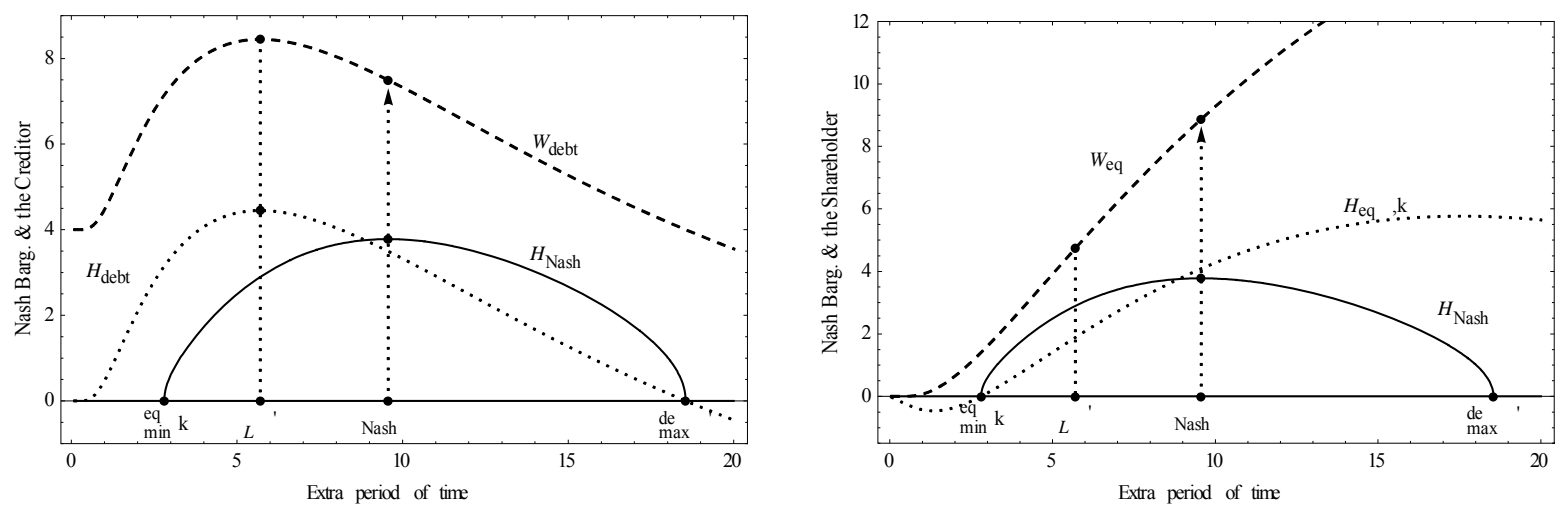

Panel B : $k=0.86$.
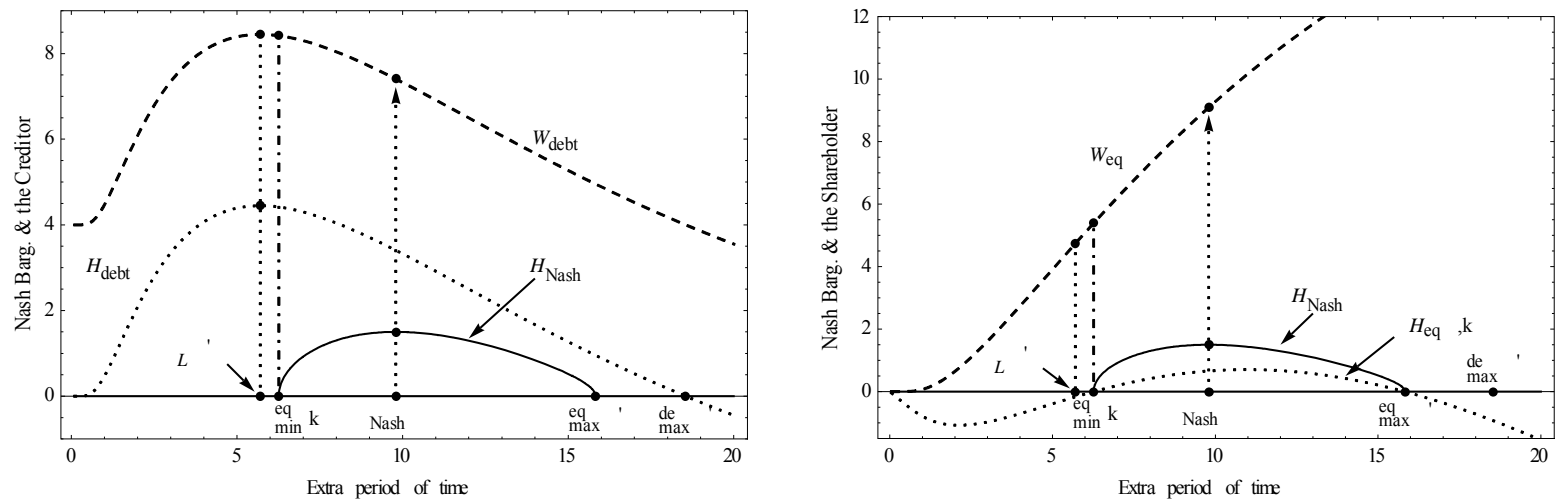

This figure plots the objective function implied by the asymmetric Nash bargaining game $\left(H_{\text {Nash }}^{\eta}(\tau)\right)$ with the other two functions that matter for stakeholders. Left graphs are associated to the creditor's viewpoint. Right graphs are associated to the shareholder's viewpoint. For illustrative purposes, parameters are $V=20, F_{1}=40$, $\sigma=30 \%, r=10 \%$, the realization rate equals 20 percent and $\eta 0.6$. The reservation price of the representative shareholder is linear with $k=0.5$ in upper graphs (panel A) and $k=0.86$ in lower graphs (panel B). 
Table 1: Rescheduling and Reservation price

\begin{tabular}{|c|c|c|c|c|c|c|c|c|c|}
\hline$\beta_{(\%)}$ & $\tau_{L}^{*}(\beta)$ & $\tau_{\max }^{\mathrm{de}}(\beta)$ & $\tau_{\min }^{\mathrm{eq}}(K)$ & $H_{\text {debt }}\left(\tau_{L}^{*}(\beta)\right)$ & $E q\left(\tau_{L}^{*}(\beta)\right)$ & $H_{\text {debt }}\left(\tau^{*}\left(V_{T_{1}}, K, \beta\right)\right)$ & $\operatorname{Eq}\left(\tau^{*}\left(V_{T_{1}}, K, \beta\right)\right)$ & $K_{\max }$ & Rescheduling \\
\hline 65 & 1.47 & 5.30 & 0.79 & 2.82 & 2.25 & 2.82 & 2.25 & 8.51 & \multirow{4}{*}{$\begin{array}{c}\text { Yes with the } \\
\text { Longstaff's } \\
\text { design }\end{array}$} \\
\hline 70 & 1.24 & 4.11 & 0.79 & 2.13 & 1.83 & 2.13 & 1.83 & 6.72 & \\
\hline 75 & 1.02 & 3.07 & 0.79 & 1.51 & 1.42 & 1.51 & 1.42 & 5.04 & \\
\hline 80 & 0.80 & 2.16 & 0.79 & 0.96 & 1.02 & 0.96 & 1.02 & 3.49 & \\
\hline 85 & 0.60 & 1.39 & 0.79 & 0.51 & 0.65 & 0.47 & 1 & 2.11 & Yes \\
\hline 90 & 0.40 & 0.77 & 0.79 & 0.19 & 0.31 & & & $0.96 *$ & No \\
\hline 95 & 0.20 & 0.30 & 0.79 & 0.02 & 0.06 & & & 0.18* & No \\
\hline
\end{tabular}

The shareholder's reservation price is set to $K=1$ Other structural parameters are those Longstaff (1990) use: $V=34, F_{1}=40, \sigma=20 \%$ and $r=6 \%$. Shaded area signals values compatible with Longstaff's findings. 